\title{
ALCANCE Y LÍMITES DE LA DEFENSA DE LA LIBERTAD DE EXPRESIÓN EN LA TEORÍA POLÍTICA DE BARUCH SPINOZA
}

\section{SCOPE AND LIMITS OF THE DEFENCE OF FREEDOM OF EXPRESSION IN BARUCH SPINOZA'S POLITICAL THEORY}

\author{
María Nieves Saldaña \\ Universidad de Huelva
}

\begin{abstract}
SUMARIO: I. INTRODUCCIÓN. BARUCH SPINOZA, LIBERTAD DE EXPRESIÓN Y LIBERALISMO DEMOCRÁTICO.- II. PACTO SOCIAL, SEGURIDAD COLECTIVA Y PODER DEL ESTADO EN LA TEORÍA POLÍTICA SPINOZISTA.- III. ALCANCE Y LÍMITES DE LA DEFENSA DE LA LIBERTAD DE EXPRESIÓN EN EL TRATADO TEOLÓGICO-POLÍTICO: OPINIONES SEDICIOSAS, SEGURIDAD COLECTIVA Y ALIENACIÓN INDIVIDUAL.- IV. LA SUPERACIÓN DEL DISCURSO SPINOZISTA EN EL ENSAYO FUNDACIONAL DE LA CONCEPCIÓN MODERNA DE LA LIBERTAD DE EXPRESIÓN: LA AREOPAGITICA DE JOHN MILTON
\end{abstract}

Resumen: Aunque en la teoría politica de Baruch Spinoza ocupa un lugar destacado la libertad de pensamiento y expresión en su aproximación al sistema democrático de gobierno, sin embargo, realmente el alcance que Spinoza confiere a la libertad de expresión está limitado por su concepción del Estado como instrumento de racionalización de la seguridad colectiva, que constituye principio fundacional en su teoría política, concibiendo la libertad de expresión como mecanismo para la pervivencia del Estado y no como garantía de la libertad individual frente al propio Estado, distanciándose así Spinoza de la concepción moderna de la libertad de expresión que funda John Milton en la Areopagitica y que adopta dos siglos más tarde John Stuart Mill en On Liberty.

\begin{abstract}
Although in Baruch Spinoza's political theory occupies a prominent place freedom of thought and expression in his approach to the democratic system of government, however, the scope that Spinoza really gives to freedom of expression is limited by its conception of the state as an instrument of rationalization of collective safety, which it is a founding principle in his political theory, because freedom of expression is conceived as a mechanism for the survival of the state and not as a guarantee of individual freedom against the state itself. Spinoza, therefore, is far from the modern conception of freedom of expression that founded John Milton in Areopagitica and endorsed John Stuart Mill in On Liberty two centuries later.
\end{abstract}

Palabras clave: Baruch Spinoza, teoría política, libertad de expresión, sistema democrático de gobierno 
Key Words: Baruch Spinoza, political theory, freedom of speech, democratic system of government

\section{INT RODUCCIÓN: BARUCH SPINOZA, LIBERTAD DE EXPRESIÓN Y LIBERALISMO DEMOCRÁTICO}

La teoría politica de Baruch Spinoza ha sido considerada una aportación fundamental para la configuración del pensamiento de la modernidad ${ }^{1}$, especialmente, sus ideas sobre la libertad de conciencia y la tolerancia religiosa así como sobre el sistema democrático de gobierno, el régimen que en su opinión en mayor medida asegura la liberación de la autonomía individual al fomentar la exteriorización de nuestras facultades racionales y comunicativas, siendo reconocido como uno de los fundadores del liberalismo democrático ${ }^{2}$. Sin embargo, aunque en la teoría política de Spinoza ocupa un lugar destacado la defensa de la libertad de conciencia y de pensamiento, hasta el punto de que constituye en gran medida el fundamento del poder político y del Estado ${ }^{3}$, no obstante, su defensa de la libertad de expresión está condicionada por el presupuesto contractualista que domina la doctrina política del holandés. En efecto, las emergentes doctrinas seculares que sobre la libertad de expresión defiende Spinoza al diseñar su aproximación al sistema democrático de gobierno en el Tractatus Theologicus-Politicus están limitadas por la consideración del pacto como mecanismo de racionalización de la seguridad colectiva, que constituye elemento fundacional en su teoría política, delimitando el ejercicio de la libertad de expresión en aras del respeto al origen contractual del sistema y fijando el limite en las expresiones sediciosas ${ }^{4}$.

Realmente, Spinoza proclama la libertad de expresión como "un mal necesario" en el Estado, por temor a que de otra manera se frustre el presupuesto ontológico del sistema político que dibuja, la seguridad colectiva. La finalidad del Estado es garantizar la seguridad, no tanto individual sino colectiva, realizable en el modelo de Estado que diseña, en el que la libertad no se conquista frente al Estado, sino en el propio Estado. Por esto, en la doctrina política diseñada por el

1 De la extensa bibliografia sobre su teoría politica, entre otros, vid. José Joaquín Jiménez Sánchez, "Los fundamentos del Estado politico en Spinoza", Análes de la Cátedra Francisco Suárez, núm. 46, 2012, pp. 211-236; Etienne Balibar, Spinoza and Politics, Verso, London, 1998; Francisco Javier Peña Echeverría, "Razón y democracia en Spinoza”, en Filosofía política. Razón e Historia, Suplementos Anthropos, núm. 28, noviembre, 1991, pp. 10-17; también de Peña Echeverria, La filosofia politica de Espinosa, Secretariado de Publicaciones, Universidad de Valladolid, 1989; Douglas J. Den Uyl, Power, State, Freedom: An Interpretation of Spinoza's Politic Philisophy, Van Gorcum, Assen, 1983; Robert J. McShea, The Political Phylosophy of Spinoza, Columbia University Press, New York, 1968.

2 Entre otros, vid. Steven B. Smith, Spinoza, Liberalism, and the Question of Jewish Identity, Yale University Press, New Haven, 1997, especialmente pp. 22-26; Dogglas Den Uyl, Stuart D. Warner, "Liberalism and Hobbes and Spinoza", Studia Spinozana, vol. 3, 1987, pp. 261-318; Joel Schwartz, "Liberalism and the Jewish Question: A Study of Spinoza and the Young Marx", Political Theory, vol. 13, 1985, pp. 58-84; Lewis Samuel Feuer, Spinoza and the Rise of Liberalism, Beacon Hill Press, Boston, 1958, especialmente p. 65.

3 Vid. Vicente Serrano, "Freedom of thought as radical freedom in Spinoza's critique of religion", Reformation and Renaissance Review, vol. 14, núm. 1, 2012, pp. 23-39.

${ }^{4}$ Al respecto vid. Leonard W. Levy, Emergence of a Free Press, Oxford University Press, Oxford, New York, 1985, pp. 89-91. 
holandés la libertad de expresión no es un límite para el Estado, antes al contrario, el Estado es el límite de la libertad de expresión, límite único y absoluto, por esto no tolera la opinión sediciosa, de ahí, que, aunque Spinoza sea consciente del carácter plural y heterogéneo que refleja la libertad de expresión, pretenda reconducirla a la unidad a través del pacto. Sin embargo, la pretensión spinozista de unidad es un proyecto inviable, el pacto es conductor de la pluralidad, no conductor a la unidad, de ahí que cuando Spinoza acepta tal concesión el núcleo del argumento a favor de la libertad de expresión decae.

Por todo, el discurso spinozista en defensa de la libertad de expresión se arbitra más como instrumento que tiende a garantizar la seguridad colectiva que como mecanismo de consagración de la autonomía y autorrealización individual. De ahí que no podamos calificar al solitario de la Haya de autor "liberal", al proyectar un concepto de "libertad positiva" sólo realizable en el Estado. Y es que el proyecto de racionalización colectiva que articula la doctrina politica del holandés conduce, paradójicamente, a la alienación individual, confirmándose que para Spinoza la libertad no es más que pura ilusión, concibiendo la libertad de expresión como un mecanismo para la pervivencia del Estado y no como un vehículo que coadyuva a la satisfacción de la dimensión racional de la individualidad y libertad humanas. De ahí que, como se analiza al final, el restrictivo discurso spinozista no tenga nada que hacer frente a la defensa de la libertad de expresión que ofreció John Milton en la Areopagitica ${ }^{5}$, predeterminada por un concepto de libertad dinámico, predicable del individuo frente al poder, preconizando así el concepto moderno de libertad que consagraría dos siglos más tarde John Stuart Mill en On Liberty.

\section{II: PACTO SOCIAL, SEGURIDAD COLECTIVA Y PODER DEL ESTADO EN LA TEORÍA POLÍTICA SPINOZISTA}

Hijo de una familia portuguesa de judíos sefardies emigrada a Holanda a principios del siglo XVII, Baruch Spinoza $(1632-1677)^{6}$ fue instruido en la tradición filosófica y religiosa del judaísmo, sin embargo, su enfoque racionalista del asunto religioso provocaría su enfrentamiento temprano con los rabinos de Ámsterdam, la acusación de ateísmo y su excomunión en 1656, cuando solo tenía 24 años, siendo declarado maldito y repudiado para siempre según reza el documento que la proclamaba, "Maldito sea de día y maldito sea de noche; maldito sea cuando se acuesta y maldito cuando se levanta; maldito sea cuando sale y maldito sea cuando regresa [...] Ordenamos que nadie mantenga con él comunicación oral o escrita, que nadie le preste ningún favor, que nadie mantenga con él comunicación oral o escrita [...] que nadie lea nada escrito o transcrito por él»" 7 . A partir de este momento se dedica por entero al estudio de pensadores tales como Descartes y Bacon, destacando entre sus obras los Principios de Filosofía de Descartes (1663), la única obra que publicó bajo su

5 Al respecto, vid. Murray Dry, "The First Amendment Freedoms, Civil Peace and the Quest for Truth", Constitutional Commentary, vol. 15, núm. 2, 1998, p. 339.

6 Sobre su vida y obra, vid. Steven Nadler, Spinoza: A Life, Cambridge University Press, Cambridge, New York, 1999.

${ }^{7}$ Reproducido en Mercedes Allendesalazar Olaso, Spinoza. Filosofia, pasiones y politica, Alianza, Madrid, 1988, p. 13. 
propio nombre en vida, los Pensamientos Metafisicos (1663), el Tratado TeológicoPolitico (1670), el Tratado Político y la Ética (ambas publicadas póstumamente en $1677)^{8}$.

Baruch Spinoza expresó sus ideas en una etapa de la historia holandesa sometida a un constante cambio politico y social ${ }^{9}$. El clima de libertad religiosa y económica que imperó bajo el gobierno de Jan de Witt condujo al florecimiento de la ciencia y de la cultura holandesa, gestándose el proceso de secularización sobre el que descansaría el discurso de la libertad de conciencia a partir de la segunda mitad del siglo XVII ${ }^{10}$, apreciándose nítidamente en la teoría política de Spinoza, donde resuena, sin duda, la teorización estatal de corte hobbesiana. Aunque la doctrina se presenta dividida a la hora de determinar el nexo intercomunicativo existente, quizás sobredimensionado ${ }^{11}$, entre la teoría política de ambos pensadores, porque mientras que ciertos autores defienden que la teorización política ofrecida por Hobbes y Spinoza es muy similar ${ }^{12}$, hay quienes niegan tal semejanza ${ }^{13}$. Tampoco es infrecuente encontrar estudios que conectan al filósofo de Ámsterdam con autores tan dispares como Maquiavelo ${ }^{14}$, Rousseau ${ }^{15}$, e, incluso, con la visión estatal hegeliana, como defiende, no falto de

8 Vid. Spinoza, Complete Works, edited, with introduction and notes by Michael L. Morgan, Hackett Publishing Company, Indianapolis, Cambridge, 2002; Steven Nadler, Spinoza: A Life, Cambridge University Press, Cambridge, New York, 1999.

9 Para un análisis de tales aspectos históricos y su posible influencia en el pensamiento spinozista, vid. Atilano Dominguez Basalo, "Spinoza", en Historia de la Teoría Politica, F. Vallespin (ed.), Alianza, Madrid, 1990-91, vol. II, pp. 313-318; Lucien Mugnier-Pollet, La philosophie politique de Spinoza, Librairie Philosophique J. Vrin, Paris, 1976, pp. 13-80; y también, Robert J. McShea, The Political Philosophy of Spinoza, op. cit., pp. 21-27.

10 Sobre este tema, entre otros, vid. Paul Hazard, La crisis de la conciencia europea (1680-1715), $4^{\mathrm{a}}$ ed., traducción de Julián Marías, Ediciones Pegaso, Madrid, 1988; José María Rodríguez Paniagua, "Las doctrinas sobre la tolerancia religiosa de fines del siglo XVII y la distinción entre moral y derecho a principios del XVIIP', Anuario de Derechos Humanos, núm. 4, 1986-87, pp. 359378; y también Henry Kamen, Nacimiento y desarrollo de la tolerancia en la Europa Moderna, Trad. de María José del Río, Alianza Editorial, Madrid, 1987.

11 "[...] del que con frecuencia se quiere hacer derivar, como si fuera un simple apéndice o continuación del de Spinoza, sobre todo por parte de aquellos que lo exponen desconectado del conjunto de su filosofia", José María Rodríguez Paniagua, "El pensamiento filosófico-politico en Spinoza y Lebniz”, Revista de Estudios Politicos (Nueva Época), núm. 36, 1983, pp. 159-179, especialmente p. 169, ensayo reeditado más tarde en su Historia del Pensamiento Juridico, Tomo I, De Heráclito a la Revolución Francesa, $6^{\mathrm{a}}$ ed., Servicio de Publicaciones, Facultad de Derecho de la Universidad Complutense, Madrid, 1988, pp. 119-142. Desde una crítica similar, vid. Stuart Hampshire, Spinoza, traducción de Vidal Peña, Alianza Universidad, Madrid, 1982, p. 132. 155 .

12 En este sentido, vid. Robert J. McShea, The Political Philosphy of Spinoza, op. cit., pp. 137-

13 Entre otros, vid. Noel Malcolm, “Hobbes and Spinoza”, en H. Burns (ed.), The Cambridge History of Political Thought, 1450-1700, Cambridge University Press, Cambridge, New York, 1991, pp. 555-556; y también Leo Strauss, Spinoza's Critique of Religion, traducción de E. M. Sinclair, Schocken, New York, 1965, p. 229. Un estudio interesante de la cuestión puede leerse en Alexander Matheron, "Lè droit du plus fort': Hobbes contre Spinoza", Revue Philosphique de la France et de 1'Etranger, vol. 110, 1985, pp. 149-176.

14 Vid. Jean Marc Gabaude, "Spinoza lettore del Machiavell”, Rivista di Filosofia Neoescolastica, vol. 62, 1970; Adolfo Ravà, "Spinoza e Machiavelli", en Studi Filosofico- Giuridice dedicati a Giorgio del Vecchio, vol. II, Modena, 1931.

15 Vid. Georg Geismann, "Spinoza beyond Hobbes and Rousseau", Journal of the History of Ideas, vol. 52, núm. 1, 1991, pp. 35 y ss.; Maledeine Frances, "Les reminiscences spinozistes dans 
razón como veremos, Peña Echeverría, "Si acaso es Hegel, creemos, el filósofo cuyo pensamiento político tiene más puntos de contacto con el de Espinosa, por su visión de los fenómenos políticos desde la perspectiva global del Estado como totalidad superior a los individuos y la consideración de la entidad estatal como lugar de objetivación del Espíritu, es decir, expresión y desarrollo de la racionalidad" 16 .

Aunque en todos los escritos del holandés se refleja el espíritu secular que comenzaba a generalizarse en la literatura politica europea de entonces, fue, sin duda, en su obra cumbre, Tractatus Theologicus-Politicus (1670), publicado solamente con sus iniciales y señalando como lugar de edición Hamburgo, cuando había sido impreso en Ámsterdam, dato que muestra la presión a que pudo verse sometido el holandés para sacar a la luz sus obras, que le lleva a publicar en el anonimato ${ }^{17}$ y a impedir la traducción holandesa del Tratado Teológico-Político en $1671^{18}$, y, curiosamente, a reivindicar la libertad de expresión ${ }^{19}$, el texto en el que Spinoza aborda la cuestión que por excelencia preocupaba a la tratadística de la época, la supuesta interconexión entre la teología y la política, argumentando en la radical distinción entre teología y filosofia, obediencia y conocimiento, fe y razón, la necesaria liberación de la religión y el entendimiento racional de sus antagonismos intrínsecos. Argumentos seculares de corte contractualista que conducirán a Spinoza a la secularización teórica de la política como "orden necesario" 20 , y a reivindicar una esfera de libertad individual, que el propio Estado, de carácter democrático, aunque contradictoriamente de tintes absolutos, tiene la obligación de respetar, aunque sólo sea para asegurar su existencia ${ }^{21}$.

le contrat social de Rousseau", Revue Philosophique, vol. 76, 1951, pp. 61-84; Paul Verniere, Spinoza et la pensée française avant la Révolution, 2 vols., Presses Universitaires de France, París, 1954.

16 Francisco Javier Peña Echeverría, La filosofía politica de Espinosa, Secretariado de Publicaciones, Universidad de Valladolid, 1989, p. 15. Para un análisis comparado, vid. Pierre Macherey, Hegel ou Spinoza, Maspero, París, 1979.

17 Para un planteamiento distinto, vid. Julie E. Cooper, "Freedom of Speech and Philosophical Citizenship in Spinoza's Theologico-Political Treatise", Law, Culture and the Humanities, vol. 2, 2006, pp. 91-114, especialmente pp. 94-95.

18 Al respecto, vid. Jonathan I. Israel, Radical Enlightenment: Philosophy and the Making of Modernity 1650-1750, Oxford University Press, Oxford, New York, 2001, pp. 275- 294.

19 Sobre la posible influencia que la experiencia vital spinozista pudiera ejercer en su pensamiento, vid. José María Rodríguez Paniagua, "El pensamiento filosófico-politico en Spinoza y Lebniz", op. cit., p. 159; y también, Roland Maspetiol, "L'Etat et le Droit selon Spinoza”, Archives de Philosphie du Droit, núm. 5, 1950, p. 157.

20 Como señala Peña Echeverría, "Espinosa realiza la segunda posibilidad, la secularización teórica de la Política. Esta secularización se opera mediante la aplicación de la categoría de necesidad. Frente al supuesto de la intervención divina en el proceso histórico-político, frente a la idea de un orden querido por Dios, pone Espinosa un orden necesario, único presupuesto que posibilita la explicación de los fenómenos sociales por sí mismos", vid. La filosofía politica de Espinosa, op. cit., p. 121.

21 Sobre el Tratado, entre los estudios más recientes vid. Susan James, Spinoza on Philosophy, Religion, and Politics: The Theological-Political Treatise, Oxford University Press, Oxford, 2012; Steven Nadler, A Book Forged in Hell: Spinoza's Scandalous Treatise and the Birth of the Secular Age, Princeton University Press, Princeton, 2011; Yitzhak Melamed, Michael A. Rosenthal (eds.), Spinoza's Theological-Political Treatise: A Critical Guide, Cambridge University Press, Cambridge, 
En efecto, el racionalismo presente en la construcción spinozista conduce a priorizar el binomio razón-libertad, "sólo es libre aquel que vive con sinceridad bajo la sola guía de la razón". Sin embargo, Spinoza es consciente de la reconocida impotencia de la razón para primar sobre las pasiones ${ }^{22}$, porque la razón se muestra incapaz de conducir por sí sola de la pasión a la libertad, de ahí que acuda al ardid del Estado para asegurar el tránsito a la libertad, "el Estado más libre será aquel cuyas leyes están fundadas en la sana razón, ya que en él todo el mundo puede ser libre» ${ }^{23}$. Concepción racionalista que conlleva a la secularización del Estado ${ }^{24}$, a su carácter necesario ${ }^{25}$, y a diseñar un origen del sistema político según el discurso contractualista, "que para vivir seguros y lo mejor posible, los hombres tuvieron que unir necesariamente sus esfuerzos [...] Por eso debieron establecer con la máxima firmeza y mediante un pacto, dirigirlo todo por el solo dictamen de la razón» 26 .

Construcción racionalista que igualmente conduce a Spinoza a defender el sistema democrático, "[...] pienso haber demostrado [...] los fundamentos del Estado democrático [...] me parecía el más natural y el que más se aproxima a la libertad que la naturaleza concede a cada individuo" ${ }^{27}$. Predilección por la democracia porque, como señala Steven B. Smith, para Spinoza la libertad democrática permite la autorrealización racional de los ciudadanos ${ }^{28}$. De ahí que

2010. Para una traducción al español, vid. Baruch Spinoza, Tratado Teológico-Politico, traducción, introducción, notas e índices de Atilano Domínguez, Alianza Editorial, Madrid, 1986, por donde se cita.

${ }^{22} \mathrm{Al}$ respecto, cfr. Atilano Domínguez, "Spinoza", en Historia de la Teoría Politica, op. cit., vol. II, p. 321 .

23 Baruch Spinoza, Tratado Teológico-Politico, op. cit., XVI, pp. 340-341. En el mismo sentido señala Francis Canavan, "The purpose of the state, as Spinoza says, is really freedom. But freedom consists in following reason, since only the rational man is truly free", vid. Freedom of Expression Purpose as Limit, Carolina Academic Press, Durham, 1984, p. 78.

24 Como señala Muller "The separation of religiosity from rationality or theology from philosophy, grounded on a principle of freedom of thought, leads Spinoza back at a somewhat higher level to his original point-the importance of a right understanding of religion and of freedom of thought in relation to the state", vid. Richard A. Muller, Great Thinkers of the Western World, Ian P. McGreal (ed.), Harper Collins, New York, 1992, pp. 217 y ss.

25 Al respecto, vid. Francisco Javier Ansuátegui Roig, Origenes doctrinales de la libertad de expresión, Universidad Carlos III de Madrid, BOE, Madrid, 1994, p. 196.

26 Baruch Spinoza, Tratado Teológico-Político, op. cit., XVI, pp. 335 y ss. La conceptualización del pacto en Spinoza conduce a sus dos fases: el pactum unionis y el pactum subjectionis, en este sentido, entre otros, vid. Francisco Javier Peña Echeverria, La filosofía politica de Espinosa, op. cit., p. 204. Sobre el tema del contrato social en Spinoza, vid. A. G. Wernham, "Le contrat social chez Spinoza", en Studia Spinoziana, vol. 3, 1993; Gioele Solari, "La doctrina del contrato sociale in Spinoza", en La filosofia politica, I. Luigi Firpo (ed.), Laterza, Bari, 1974, pp. 195 y ss. Para un análisis comparativo de la teoría contractualista formulada por Hobbes y Spinoza, vid. José García Leal, J., "La teoría del contrato social: Spinoza frente a Hobbes", Revista de Estudios Politicos, vol. 28, 1982, pp. 125-193.

27 Baruch Spinoza, Tratado Teológico-Politico, XVI, op. cit., pp. 341. En el mismo sentido Feuer cree ver en la figura de Spinoza el primer filósofo político de la era moderna en confesarse un demócrata por su creencia en la libertad, cfr. Lewis Samuel Feuer, Spinoza and the Rise of Liberalism, op. cit., pp. 101-107.

28 Steven B. Esmith, "Spinoza's Democratic Turn: Chapter 16 of the 'Theological-Political Treatise", The Review of Metaphysics, vol. 48, 1994, pp. 359 y ss., especialmente p. 359. Para un análisis comparativo vid. Frank Tindal, "Hobbes, Spinoza, Rousseau et la formation de l'idée de 
un importante sector de spinozistas coincidan en afirmar que la doctrina politica formulada por Spinoza tiene como único objetivo definir cuál es "El verdadero fin del Estado [...] la libertad" 29 . Afirmado en este sentido Smith que a diferencia del escepticismo antropológico hobbesiano - erróneamente a mi parecer, porque sin duda la mayor conexión que presentan las doctrinas politicas formuladas por Hobbes y Spinoza es su pesimismo antropológico-, Spinoza no centra en la evitación del conflicto el principal fin de la vida en sociedad, antes al contrario, el holandés defiende el sistema democrático porque es el régimen que más asegura la liberación de la autonomía individual, fomentando la exteriorización de nuestras facultades racionales y comunicativas ${ }^{30}$.

Con todo, la principal objeción que ha apuntado la doctrina crítica de la teoria politica spinozista es el carácter absoluto que presenta la necesaria transferencia del poder, esto es, la cesión de los derechos naturales del individuo al Estado en la firma del pacto:

" [...] como el derecho natural de cada uno sólo está determinado por su poder, se sigue que, en la medida en que alguien, por fuerza o espontáneamente, transfiere a otro parte de su poder, le cederá necesariamente también, y en la misma medida, parte de su derecho. Por consiguiente tendrá el supremo derecho sobre todos, quien posea el poder supremo»31.

Carácter absoluto que deviene como resultado de la transferencia incondicionada del derecho al soberano a que obliga la naturaleza pasional de la condición humana ${ }^{32}$. En efecto, siguiendo la tradición platónica, Spinoza reconoce dos atributos fundamentales de la naturaleza humana, diversa y heterogénea: la pasión, que tiende a la satisfacción del poder — no se olvide que en la concepción spinozista el poder se identifica con el derecho natural-, y la

démocratie comme mesure de la légitimité du pouvoir politique", Revue Philosophique de la France et de l'Etranger, vol. 110, 1985, pp. 195-222.

29 Baruch Spinoza, Tratado Teológico-Politico, op. cit., XX, p. 411.

30 Como señala Smith, "[...] the Treatise help out a more positive role for politics than the avoidance of the summun malum. Spinoza endorses the democratic republic because it is the regime most consistent with the autonomous individual liberated [...] Democracy is desiderable because it fosters the conditions for reason and the expression of our individual faculties", vid. Steven B. Smith, "Spinoza's Democratic Turn: Chapter 16 of the "Theological-Political Treatise", op. cit., p. 360. Sobre el concepto de libertad en Spinoza, vid. S. Paul Kashap, Spinoza and Moral Freedom, State University of New York Press, Albany, 1987; Stuart Hampshire, Spinoza and the Idea of Freedom, London, 1961.

31 Baruch Spinoza, Tratado Teológico-Politico, op. cit., XVI, pp. 337-338.

32 Al respecto vid. Gioele Solari, "La doctrina del contrato sociale in Spinoza", op. cit., p. 227. Por su parte, Peña Echeverria afirma que en la doctrina spinozista "el individuo no renuncia al derecho natural al pasar a formar parte de la sociedad civil", antes al contrario "Lo que era en el estado natural derecho abstracto se convierte en el Estado civil en ejercicio concreto del propio conatus", vid. La filosofía politica de Espinosa, op. cit., pp. 206-207. Para un intento de superar la evidente contradicción que presenta el dualismo democracia-estado absoluto, vid. Francisco Javier Ansuátegui Roig, "El concepto de poder en Espinoza: individuo y estado", Revista de Estudios Políticos, (Nueva Época), núm. 100, 1988, pp. 142 y ss.; y también en sentido similar, Atilano Dominguez, "Libertad y democracia en la filosofia politica de Spinoza", Revista de Estudios Políticos, (Nueva Epoca), núm. 11, 1979, pp. 144 y ss. Un estudio comparativo del modelo absoluto de Estado diseñado por Hobbes y Spinoza puede consultarse en Emilia GiancottiBoscherini, "La teoria dell'assolutismo in Hobbes e Spinoza”, en Studia Spinoziana, vol. 1, 1985. 
dimensión racional, reflejándose así el carácter ambivalente que manifiesta su teoría politica ${ }^{33}$. Mas la realidad muestra la primacía de la primera sobre la razón, "[...] la naturaleza humana está constituida de forma [que] todos buscan su propia utilidad, más no porque la dicte la sana razón, sino [...] porque [...] se dejan arrastrar por el solo placer y por las pasiones", de ahí que para el holandés "El derecho natural de cada hombre no se determin[e], pues, por la sana razón, sino por el deseo y el poder" ${ }^{34}$. Primacía del elemento pasional sobre el racional que condicionará el contenido del derecho natural ${ }^{35}$, distanciándose así Spinoza de la tradición aristotélica, ciceroniana y tomista, y acercándose a la concepción hobbesiana, basada en el deseo y el poder ${ }^{36}$. De ahí que Ansuátegui Roig niegue el atributo racional al concepto de libertad spinozista, "Este derecho natural, al igual que la propia idea de deseo, es axiológicamente neutra: el individuo no tiene capacidad de elección a la hora de realizar una determinada actuación, no obra con libertad [...] El derecho natural de cada individuo, por consiguiente, no está constituido por la razón; por el contrario, está determinado por el deseo y el poder» ${ }^{37}$.

Gobierno de las pasiones que conduce a una situación de total inseguridad, obligando a la institucionalización de Derecho y de la fuerza, "De donde resulta que ninguna sociedad puede subsistir sin autoridad, sin fuerza y por tanto sin leyes que moderen y controlen el ansia de placer y los impulsos desenfrenados ${ }^{38}$. Emergiendo así el pacto como mecanismo de racionalización y de institucionalización de la seguridad ${ }^{39}$, "si consideramos, además, que, sin la ayuda mutua, los hombres viven necesariamente en la miseria y sin poder cultivar la razón [...] los hombres tuvieron que unir necesariamente sus esfuerzos ${ }^{40}$. Acercándose en esto la construcción spinozista, como señala García Leal, al conocido estado de guerra latente definido por Hobbes, "En dicho estado

33 Como señala Atilano Dominguez, "El dualismo entre la imaginación y la razón, entre el ignorante y el sabio, es la clave de la dinámica que late en la ética y en la política spinozianas", vid. "Libertad y democracia en la filosofía politica de Spinoza", op. cit., p. 133.

34 Baruch Spinoza, Tratado Teológico-Politico, op. cit., V, p. 157, y XVI, p. 333.

35 "[...] la conceptualización de la naturaleza [...] deriva de un procedimiento inductivo ¡procede de lo que hay¡-, nunca de una reflexión deductiva — ¡lo que debe serj-. [Spinoza] Niega la construcción del hombre natural por la razón [...] el hombre spinozista se va a fundamentar epistemológicamente sobre el eje lógico modal de las pasiones", Enrique Olivas, Eduardo DíazOtero y Joaquín Almoguera, "El hombre natural y la prudencia politica. (Anotaciones sobre la modernidad de B. de Spinoza y el proceso politico)", Revista de Estudios Políticos, (Nueva Época), núm. 95, 1997, p. 301. En el mismo sentido, vid. Atilano Domínguez, "Spinoza", en Historia de la teoría politica, op. cit., vol. II, p. 321.

36 Cfr. Antonio Truyol y Serra, Historia de la Filosofía del Derecho y del Estado, 2 vols., Alianza Editorial, $7^{\text {a }}$ ed., Madrid, 1982, vol. II, Del Renacimiento a Kant, pp. 230-232.

37 Francisco Javier Ansuátegui Roig, "El concepto de poder en Spinoza: individuo y Estado", op. cit., pp. 140-141. En el mismo sentido, vid. José García Leal, "La teoría del contrato social: Spinoza frente a Hobbes", op. cit., pp. 149-153.

38 Baruch Spinoza, Tratado Teológico-Politico, op. cit., V, pp. 157-158.

39 Como señala A. Dominguez, "El miedo común a la inseguridad y a la esclavitud, la común esperanza de la paz y la libertad son el medio natural, el humus efectivo en el que prende y se desenvuelve el pacto social", vid. "Libertad y democracia en la filosofía politica de Spinoza", op. cit., p. 139.

40 Baruch Spinoza, Tratado Teológico-Politico, op. cit., XVI, p. 335. 
prima sobre cualquier otra cosa el egoísmo pasional. Spinoza en ningún momento habla de una agresividad positiva y conformadora esencial de la conducta; con lo cual no se excluye que el egoísmo degenere en agresividad. Podemos, por tanto, suponer que el estado de naturaleza comporta [...] una situación de guerra latente de todos contra todos. Aunque Spinoza no subraya explícitamente este rasgo, se deduce de su descripción. Además, él indica reiteradamente que la finalidad consciente del contrato social es "la seguridad y la paz", justamente la negación simétrica de la guerra latente y permanente»" ${ }^{41}$. De ahí que la consideración del pacto como vehículo de institucionalización de la seguridad colectiva sea elemento clave en la teoria contractualista spinozista ${ }^{42}$. Ideas todas que el holandés sintetizó en su obra maestra, la Ética:

"Así, pues, para que los hombres puedan vivir concordes y prestarse ayuda, es necesario que renuncien a su derecho natural y se presten reciprocas garantías de que no harán nada que pueda dar lugar a daño ajeno [...] podrá establecerse una sociedad a condición de que ésta reivindique para sí el derecho, que cada uno detenta, de tomar venganza y de juzgar acerca del bien y del mal, teniendo así la potestad de dictar leyes y de garantizar su cumplimiento, no por medio de la razón, que no puede reprimir los afectos, sino por medio de la coacción. Esta sociedad, cuyo mantenimiento está garantizado por las leyes y por el poder de conservarse, se llama Estado, y los que son protegidos por su Derecho se llaman ciudadanos» 43 .

Dominio de las pasiones y principio de seguridad que vertebran axiológicamente la construcción política del holandés y que influirán notablemente en el discurso spinozista a favor de la libertad de expresión, derecho al que dedica el Capítulo XX y último del Tratado Teológico-Politico, proclamando con aparentes ecos areopagiticos en su título -aunque sólo aparentes como veremos más adelante-, que "En un Estado libre está permitido que cada uno piense lo que quiera y diga lo que piense ${ }^{44}$.

41 José García Leal, "La teoria del contrato social: Spinoza frente a Hobbes”, op. cit., pp. 137-138. Igualmente, Peña Echeverría aproxima el discurso spinozista al hobbesiano, alejándolo del estado de naturaleza rousseauniano, "Espinosa considera que la situación de los hombres en estado de naturaleza es la guerra. En este punto está mucho más cerca de Hobbes que de las tesis rousseaunianas acerca de la condición natural del hombre", vid. La filosofía política de Espinosa, op. cit., p. 193. Asimismo, vid. Atilano Dominguez, “Spinoza”, op. cit., pp. 327-328.

42 Como señala Smith, "The good for human beings is to live in society because society makes self-preservation and hence liberation from fear a positive reality [...] From Spinoza, the contract derives from no pre-existing moral obligation, but only out of the convenience of the parties seeking security from conditions of uncertainty", vid. Steven B. Smith, "Spinoza's Democratic Turn: Chapter 16 of the 'Theological-Political Treatise”, op. cit., pp. 359 y ss.

43 Baruch Spinoza, Ética demostrada según el orden geométrico, introducción, traducción y notas de Vidal Peña, Alianza, Madrid, 1987, IV, proposición XXXVII, p. 292. Para su estudio, entre otros, vid. Olli Koistinen, The Cambridge Companion to Spinoza's Ethics, Cambridge University Press, Cambridge, 2009; Steven Nadler, Spinoza's Ethics: An Introduction, Cambridge University Press, Cambridge, 2006; Steven B. Smith, Spinoza's Book of Life: Freedom and Redemption in the Ethics, Yale University Press, New Haven and Longon, 2003.

${ }^{44}$ Baruch Spinoza, Tratado Teológico-Politico, op. cit., XX, p. 408. 


\section{ALCANCE Y LÍMITES DE LA LIBERTAD DE EXPRESIÓN EN EL TRATADO TEOLÓGICO-POLÍTICO: OPINIONES SEDICIOSAS, SEGURIDAD COLECTIVA Y ALIENACIÓN INDIVIDUAL}

Realmente, a priori, el discurso de Spinoza en defensa de la libertad de expresión ${ }^{45}$ está determinado por el presupuesto iusnaturalista que informa la doctrina política del holandés, al predicar el carácter inalienable de ciertos derechos naturales en el Prefacio del Tratado Teológico-Político, "Mas, como nadie puede privarse a sí mismo de su poder de defenderse, hasta el punto de dejar de ser hombre, concluyo de ahí que nadie puede privarse completamente de su derecho natural, sino que los súbditos retienen, por una especie de derecho de naturaleza, algunas cosas, que no se les pueden quitar sin peligro para el Estado"46. Argumentos que reitera en el Capítulo XVII, "nadie podrá transferir a otro su poder ni, por tanto, su derecho hasta el punto de dejar de ser hombre, ni existirá jamás una potestad suprema que pueda hacerlo todo tal como quiera", de tal modo que la cesión del derecho de autodefensa no impide la reserva de ciertas parcelas a la autonomía individual, "Hay que conceder, pues, que cada uno reserve muchas parcelas de su derecho, las cuales dependerán, por tanto, de su propia decisión y no de la ajena» ${ }^{4}$.

Ámbito subjetivo intransferible en el que la libertad de pensamiento constituye la primera esfera del derecho natural inalienable, "Por el contrario, en un estado libre no cabría imaginar ni comprender nada más desdichado, ya que es totalmente contrario a la libertad de todos adueñarse del libre juicio de cada cual mediante prejuicios o coaccionarlo de cualquier forma" ${ }^{48}$. Defendiendo asi Spinoza la libertad de pensamiento como condición esencial de la vida política ${ }^{49}$,

45 Para un análisis de la concepción spinozista sobre la libertad de expresión, entre otros, vid. Paola de Cuzzani, "Baruch Spinoza: Democracy and Freedom of Speech", en G. Floistad (ed.), Philosophy of Justice, Contemporary Philosophy: A New Survey, Springer Science, 2015, pp. 95118; Julie E. Cooper, "Freedom of Speech and Philosophical Citizenship in Spinoza's TheologicoPolitical Treatise", Law, Culture and the Humanities, vol. 2, 2006, pp. 91-114, especialmente pp. 94-95; Bruce Bubacz, "Constitutive Free Speech Justifications: Spinoza's Arguments form Human Nature and Personal Merit", Free Speech Yearbook, vol. 32, 1994, pp. 146-164; Deleuze Gilles, Expressionism in Philosophy: Spinoza, Martin Joughin (trad.), MIT Press, New York, 1990; Javier de Lucas, "Nota sobre libertad de expresión y democracia en la obra de Spinoza", Doxa, núm. 5, 1988, pp. 355-363; Edward I. Pitts, "Spinoza on Freedom of Expression", Journal of the History of Ideas, vol. XLVII, núm. 1, 1986, pp. 21 y ss; Francis Canavan, Freedom of Expression Purpose as Limit, op. cit., cap. IV, pp. 72-79; Francisco Javier Ansuátegui Roig, Orígenes doctrinales de la libertad de expresión, op. cit., pp. 205-226; y también, Jean Préposiet, "Libéralisme et sédition. Note sur le chapitre XX du Tractatus Theologico-Politicus”, en Giornale Critico della Filosofia Italiana, núm. 3-4, 1977, pp. 500-505.

46 Baruch Spinoza, Tratado Teológico-Politico, op. cit., Prefacio, p. 71.

47 Ibíd., XVII, pp. 350-351. Sobre tal "limite de independencia", vid. Francisco Javier Peña Echeverria, La Filosofía Política de Espinosa, op. cit., p. 379. Sobre la cuestión de la transferencia del derecho al Estado, vid. Christian Lazzeri, Droit, pouvoir et liberté: Spinoza critique de Hobbes, Presses Universitaires de France, 1998, pp. 155-240.

48 Baruch Spinoza, Tratado Teológico-Politico, op. cit., Prefacio, p. 65. Al respecto, vid. Francisco Javier Ansuátegui Roig, Orígenes doctrinales de la libertad de expresión, op. cit., pp. 207-209; y también, Francisco Javier Peña Echeverria, La filosofía política de Espinosa, op. cit., p. 382.

49 Al respecto José Joaquín Jiménez Sánchez afirma que "la libertad de pensamiento exigirá para Spinoza la libertad de expresión", en "Los fundamentos del Estado politico en Spinoza", op. cit., pp. 212 y 232. En esta línea, vid. también John Locke, Carta sobre la tolerancia, Pedro Bravo Gala (ed.), $3^{\mathrm{a}}$ ed., Tecnos, Madrid, 1994, p. xxx. 
de ahí la conceptualización de la libertad de expresión como derecho natural inalienable, "[...] nadie puede transferir a otro su derecho natural o su facultad de razonar libremente y de opinar sobre cualquier cosa, ni ser forzado a hacerlo" 50 .

Sin embargo, el carácter inalienable de tal esfera de libertad ha de ser objeto de ciertas consideraciones. En efecto, el contrato spinozista, mecanismo de institucionalización del Estado democrático, tendrá únicamente por objeto los actos, pero no el juicio, "En el estado democrático (el que más se aproxima al estado natural) todos han hecho el pacto, según hemos probado, de actuar de común acuerdo, pero no de juzgar y razonar"51. De ahí que Spinoza se refiera solamente al primer ámbito del derecho natural que no se transfiere, la libertad de juzgar y razonar, " [...] cada uno es, por el supremo derecho de la naturaleza, dueño de sus pensamientos» ${ }^{52}$, confirmándose que Spinoza piensa, ante todo, en la libertad de pensamiento ${ }^{53}$. Porque, realmente, Spinoza incluye la libertad de expresión en la parcela reservada a plena disponibilidad como consecuencia de su interpretación de la naturaleza humana, inclinada a pensar y expresar lo que piensa, "ni los más versados, por no aludir siquiera a la plebe, saben callar", y como derecho natural que es, dominado más por la pasión que por la razón o virtud, "Es éste un vicio común a los hombres: confiar a otros sus opiniones, aun cuando sea necesario el secreto" 54 , de ahí que considere la pluralidad de opiniones irremediable manifestación de la diversidad humana, "No obstante [...] nunca se ha logrado que los hombres no experimenten que cada uno posee suficiente juicio y que existe tanta diferencia entre las cabezas, como entre los paladares", realidad necesariamente reflejada en el acuerdo de voluntades, "Aunque se admita [...] que las supremas potestades tienen derecho a todo y que son intérpretes del derecho [...] nunca podrán lograr que los hombres no opinen cada uno a su manera" 55 , porque las opiniones humanas no se pueden reducir a la unidad o a la uniformidad ${ }^{56}$, antes al contrario, la aceptación de su diversidad contribuye a mantener la paz y la seguridad, porque si el individuo es privado de tal libertad, atributo natural, se provocaría tal discordia que si el Estado no la reconoce está perdido, de ahí que "nunca se puede intentar en un Estado, sin condenarse a un rotundo fracaso, que los hombres sólo hablen por prescripción de las supremas potestas, aunque tengan opiniones distintas y contrarias" 57 , conceptualizándose así la libertad de expresión como una necesidad y un derecho ${ }^{58}$.

50 Baruch Spinoza, Tratado Teológico-Político, op. cit., XX, p. 408. Incidiendo en el carácter inalienable de la libertad de expresión, vid. Christian Lazzeri, Droit, pouvoir et liberté: Spinoza critique de Hobbes, op. cit., pp. 238-240.

51 Ibid., p. 417.

52 Ibid., p. 410.

53 Ibid., p. 350, nota 351.

${ }^{54}$ Ibid., p. 410.

55 Ibid., p. 409.

56 Al respecto, vid. Francisco Javier Ansuátegui Roig, Origenes doctrinales de la libertad de expresión, op. cit., p. 210.

${ }^{57}$ Baruch Spinoza, Tratado Teológico-Politico, op. cit., XX, p. 410.

58 Al respecto, vid. Francisco Javier Ansuátegui Roig, Orígenes doctrinales de la libertad de expresión, op. cit., p. 216. En el mismo sentido, vid. Javier de Lucas, "Nota sobre libertad de 
Y aquí termina la teorización aparentemente liberal que ofrece Spinoza. En efecto, el objetivo último del Tratado Teológico-Político es demostrar que no debe haber contraposición alguna entre la libertad de expresión -más que la libertad de pensamiento, por su inocuidad- y los fines del Estado, señalando en el Prefacio "que esa misma libertad puede y debe ser concedida, sin menoscabo de la paz del Estado y del derecho de los poderes supremos, y que no puede ser abolida sin gran peligro para la paz y sin gran detrimento para todo el Estado" 59 . Conjugación teleológica que alcanza significado en el concepto clave de la teoría politica spinozista, la naturaleza humana, dirigida hacia tres fines básicos, "Todo cuando deseamos honestamente, se reduce a estos tres objetos principales, a saber, entender las cosas por sus primeras causas, dominar las pasiones o adquirir el hábito de la virtud y, finalmente, vivir con seguridad y con un cuerpo sano", y si la satisfacción de los dos primeros "reside en la misma naturaleza humana", la conquista de los medios que permiten vivir seguros se alcanza en la sociedad, "para vivir en seguridad y evitar los ataques de los otros hombres [...] la razón y la experiencia no nos han enseñado nada más seguro, que formar una sociedad" 60 . Y si la finalidad perseguida con la institucionalización de la sociedad y el Estado, como reafirma en el Capítulo $\mathrm{V}$ de su obra póstuma e inconclusa, el Tratado Político (1677), "no es otro tanto que la paz y la seguridad de la vida" ${ }^{61}$, ¿Cómo debe interpretarse entonces el pasaje más célebre del Tratado TeológicoPolitico?:

"De los fundamentos del Estado, anteriormente explicados, se sigue, con toda evidencia, que su fin último no es dominar a los hombres ni sujetarlos por el miedo y someterlos a otro, sino por el contrario, librarlos a todos del miedo para que vivan, en cuanto sea posible, con seguridad; esto es, para que conserven al máximo este derecho suyo natural de existir y de obrar sin daño suyo ni ajeno. El fin del Estado, repito, no es convertir a los hombres de seres racionales en bestias o autómatas, sino lograr más bien que su alma (mens) y su cuerpo desempeñen sus funciones con seguridad [...] El verdadero fin del Estado es, pues, la libertad»62.

Interpretación que no sólo ha de conjugar las doctrinas politicas de ambos escritos spinozistas ${ }^{63}$, sino también resolver la tensión siempre presente en el

expresión y democracia en la obra de Spinoza", op. cit., p. 361. Igualmente, Jean Préposiet señala que la libertad de conciencia en Spinoza no se define como un derecho "mais plutôt comme la manifestation d'une véritable nécessité ontologique", vid. "Libéralisme et sédition. Note sur le chapitre XX du Tractatus Theologico-Politicus”, op. cit., pp. 13-14.

59 Baruch Spinoza, Tratado Teológico-Politico, op. cit., Prefacio, p. 71.

60 Ibid., III, pp. 119-120.

61 Baruch Spinoza, Tratado Politico, traducción, introducción, notas e índices de Atilano Dominguez, Alianza, Madrid, 1986, p. 119. Y de nuevo, Spinoza señala, "la virtud del Estado es la seguridad", ibid., p. 82.

62 Baruch Spinoza, Tratado Teológico-Politico, op. cit., XX, p. 411. En este sentido, vid. Murray Dry, "The First Amendment Freedoms, Civil Peace and the Quest for Truth", Constitutional Commentary, vol. 15, núm. 2, 1998, p. 336-337, nota 50.

63 "[...] ambas obras deben leerse de un modo conjunto y complementario. Entre otras cosas, porque las perspectivas no son básicamente idénticas. El Tratado Politico toma como punto de partida algunos de los principios sentados en el Tratado Teológico-Politico, pero mientras que en el Tratado Teológico-Político la perspectiva que prima es la de las características constitutivas y la fundamentación del Estado que mejor respeta la libertad de conciencia, en el Tratado Politico se 
binomio libertad-seguridad, esto es, resolver, la primacía axiológica de la una sobre la otra ${ }^{64}$. Porque, como señalamos más arriba, aunque el principal mérito atribuido al Tratado Teológico-Politico ha sido la defensa del sistema democrático por el valor que se le otorga a la idea de libertad, sin embargo, el Tratado ofrece un concepto de libertad basado no tanto en la ausencia de impedimentos externos, "Quizá alguien piense, sin embargo, que de este modo convertimos a los súbditos en esclavos, por creer que es esclavo quien obra por un orden, y libre quien vive a su antojo"65, - dimensión de la libertad que parece ajustarse a la conocida tipología que célebremente acuñara Isaiah Berlin, quien encuadra a Spinoza en el ámbito de los defensores, entre otros Hegel y Marx, de la que denomina libertad positiva, y por tanto, entre los enemigos de la plena libertad66, sino en la obediencia a la razón misma, guiada por el criterio de la utilidad, "[...] en realidad, quien es llevado por sus apetitos y es incapaz de ver ni hacer nada que le sea útil, es esclavo al máximo; y sólo es libre aquel que vive con sinceridad bajo la sola guía de la razón»67, confirmándose que la utilidad de la

analizan los rasgos de la organización estatal, desarrollando las peculiaridades de los regímenes monárquico, aristocrático y democrático", Francisco Javier Ansuátegui Roig, "El concepto de poder en Spinoza: individuo y Estado", op. cit., p. 135. Desde una posición similar, vid. Mercedes Allendesalazar Olaso, Spinoza. Filosofía, pasiones y politica, op. cit., pp. 91-93. Por su parte, Peña Echeverría sostiene que la diferente conceptualización es consecuencia de cierta evolución en el pensamiento de Spinoza, vid. La filosofía politica de Espinosa, op. cit., p. 266. Para un estudio de la posible evolución que reflejan las doctrinas politicas de Spinoza en estos dos tratados, vid. Alexandre Matheron, "Le problème de l'évolution de Spinoza du Traité Théologico-Politique au Traité Politique," en E. Curley y P. Moreau (eds.) Spinoza Issues and Directions, E. J. Brill, Leyden, 1990.

64 Realmente, la manifiesta tensión en la doctrina axiológica spinozista entre libertad y seguridad ha sido objeto de diversas interpretaciones que aspiran a conjugar ambos fines, vid. Francisco Javier Peña Echeverria, La filosofía política de Espinosa, op. cit., pp. 266-267. En un intento de decantarse por el concepto de libertad, señala Ansuátegui Roig, "el fin del Estado no es el sometimiento violento de los súbditos ni su conversión en seres desprovistos de individualidad propia y autónoma, todo ello en aras de la seguridad y de la paz. Por el contrario, el Estado está destinado a lograr que los hombres se desenvuelvan en libertad como tales, conjugando la existencia de cada uno con la de los demás conforme a un uso libre de la razón", vid., Orígenes doctrinales de la libertad de expresión, op. cit., p. 214. En un sentido similar, vid. Norberto Bobbio, "El modelo iusnaturalista", en Estudios de Historia de la Filosofia: de Hobbes a Cramsci, traducción de Juan Carlos Bayón, Debate, Madrid, 1985, p. 126.

65 Baruch Spinoza, Tratado Teológico-Político, XX, op. cit., p. 340.

66 Cfr. Isaiah Berlin, "Two concepts of Liberty", en Four Essays on Liberty, Oxford University Press, Oxford, 1975, pp. 142, 146-147, hay traducción al español, vid. Isaiah Berlin, "Dos conceptos de libertad", en Cuatro ensayos sobre la libertad, trad. de Julio Bayón, Alianza Universidad, Madrid, 1988, pp. 187-243. En esta línea, vid. también, Edward I. Pitts, "Spinoza on Freedom of Expression", op. cit., p. 22. Para un intento de rescatar a Spinoza de tal clasificación, vid. David West, "Spinoza on Positive Freedom", Political Studies, vol. 39, 1993, pp. 284-296; y también Gerald M. Mara, "Liberal Politics and Moral Excellence in Spinoza's Political Philosophy", Journal of the History of Philosophy, vol. 22, 1982, pp. 129-150.

67 Baruch Spinoza, Tratado Teológico-Político, XX, op. cit., p. 340. Con acierto señala A. Domínguez que en Spinoza "van unidas la sumisión del apetito a la razón y la propia utilidad. Este es el criterio para discernir entre esclavitud y libre obediencia, entre el gobernante y el tirano", op. cit., p. 340, nota 340. En este sentido, Smith deriva del racionalismo intrinseco al sistema spinozista un concepto diferente de libertad positiva, "Where Spinoza most clearly differs from Hobbes and the negative libertarian tradition is in his understanding of the relation between freedom and rationality. Rationality is not simply a means to the satisfaction of our desires and inclinations [...] Reason is rather essential for an internally related to the full development of individual liberty", vid. "Spinoza's Democratic Turn: Chapter 16 of the Theological-Political Treatise", op. cit., pp. 359 y ss. 
obediencia a la autoridad es el dato que convence al individuo de su conveniencia ${ }^{68}$, porque, si la razón tiende a la conquista de la paz y la paz requiere el establecimiento de la sociedad, la libertad consiste, entonces, en obedecer las leyes derivadas de la organización social, reflejándose así en la doctrina politica spinozista la paradoja de identificar libertad con obediencia, porque si no hay obediencia no habrá más que caos y una pérdida completa de la libertad ${ }^{69}$ :

"En cualquier ciudad que el hombre viva puede ser libre. Es cierto que el hombre sólo es libre en la medida en que es guiado por la razón. Ahora bien (adviértase que Hobbes es de otra opinión), la razón aconseja plenamente la paz, y ésta no se puede alcanzar sin que se mantengan inviolados los derechos comunes de la ciudad. Por consiguiente, cuanto más se guía el hombre por la razón, es decir, cuanto más libre es, con más firmeza observará los derechos de la ciudad y cumplirá los mandatos de la suprema potestad de la que es súbdito» 70 .

Por todo, Spinoza parece priorizar el segundo término del binomio libertad individual-seguridad colectiva (individuo-Estado), en aras de mantener la paz social, priorización axiológica que determinará toda la teoría política del holandés y su discurso final en defensa de la libertad de expresión, aunque nada mejor para su ejemplificación que el pasaje escrito por el mismo Spinoza:

" $[\ldots]$ se puede formar una sociedad y lograr que todo pacto sea siempre observado con máxima fidelidad, sin que ello contradiga al derecho natural, a condición de que cada uno transfiera a la sociedad todo el derecho que él posee, de suerte que ella sola mantenga el supremo derecho de la naturaleza a todo, es decir, la potestad suprema, a la que todo el mundo tiene que obedecer, ya por propia iniciativa, ya por miedo al máximo suplicio» ${ }^{71}$.

En efecto, siendo la libertad de opinión la manifestación externa de la libertad de pensamiento ${ }^{72}$, si la segunda, interna, es neutra para el Estado, pues

68 En este sentido, vid. Francisco Javier Ansuátegui Roig, Origenes doctrinales de la libertad de expresión, op. cit., p. 200.

69 Al respecto señala Smith, "Spinoza is clearly aware of the paradox of this formula that seems to identify freedom with obedience. Merely by the fact that we obey the government, we become free since the alternative would be chaos and hence a complete loss of freedom", Steven B. Smith, "Spinoza's Democratic Turn: Chapter 16 o the 'Theological-Political Treatise”, op. cit., pp. 359 y ss.

70 Baruch Spinoza, Tratado Teológico-Politico, op. cit., XX, p. 340, nota marginal añadida por Spinoza.

71 Ibid., XX, p. 338.

72 Como señala Ansuátegui Roig, "la libertad de expresión constituye un postulado que se deriva directa, implícita y automáticamente de la libertad de pensamiento. Cuando Spinoza habla de libertad de pensamiento está hablando también de libertad de expresión, ya que es tan natural en el hombre la libertad de pensar como la libertad de expresar lo pensado. El pensamiento se prolonga en la expresión, de la misma manera que la libertad de pensamiento se prolonga en la libertad de expresión", vid. Origenes doctrinales de la libertad de expresión, op. cit., pp. 207-208. En igual sentido, vid. también Francisco Javier Peña Echeverría, La filosofía politica de Espinosa, op. cit., p. 382; y Lucien Mugnier-Pollet, La philosophie politique de Spinoza, Librairie Philosophique J. Vrin, París, 1976, p. 164. 
el pensamiento es políticamente inocuo ${ }^{73}$, la primera, externa, no lo es, porque, aunque Spinoza parece acudir en el Prefacio del Tratado Teológico-Político a la contemporánea distinción entre acción-expresión para defender la inocuidad de la libre opinión ${ }^{74}$ :

"En cuanto a las sediciones suscitadas so pretexto de religión, surgen exclusivamente porque se dan leyes sobre cuestiones teóricas y porque las opiniones - al igual que los crimenes - son juzgadas y condenadas como un delito. La verdad es que sus defensores y simpatizantes no son inmolados a la salvación pública, sino tan sólo al odio y a la crueldad de sus adversarios. Pues si el Estado estableciera por ley que sólo se persiguieran los actos y que las palabras fueran impunes, ni cabría disfrazar tales sediciones de ningún tipo de derecho, ni las controversias se transformarian en sediciones»75.

Sin embargo, el holandés vacía de contenido tal distinción en el Capítulo XX al afirmar expresamente "No podemos, no obstante, negar que también la majestad puede ser lesionada, tanto con las palabras como con los hechos" ${ }^{76}$. Y aunque por naturaleza "[sea] imposible quitar totalmente esta libertad a los súbditos", el carácter absoluto del Estado spinozista avisa que "sería, en cambio, perniciosísimo concedérsela sin límite alguno" 77 , confirmándose así que la libertad de pensamiento y expresión encuentran sus límites en la raíz de la fundamentación del Estado ${ }^{78}$, ya que una libertad total no es compatible con el carácter absoluto del poder ${ }^{79}$. De ahí que, con razón, Canavan afirme que la previa conceptualización ilimitada del derecho, no signifique, sin embargo, que el gobierno soberano no pueda ejercer un derecho de control sobre la expresión del pensamiento, antes al contrario, el carácter limitado del derecho es una derivación de la teoría política spinozista en la que poder y derecho son idénticos, porque el derecho a expresarse libremente sólo es concebible en relación con los derechos del soberano ${ }^{80}$.

73 En este sentido, vid. Francisco Javier Peña Echeverría, La filosofía politica de Espinosa, op. cit., p. 380.

74 Vid. Thomas I. Emerson, Toward a General Theory of the First Amendment, Vintage Books, New York, 1967, pp. 60-61. Edward I. Pitts enlaza las doctrinas spinozistas con el discurso contemporáneo de Emerson, "Spinoza is working toward the distinction between expression and action noted as the core to any absolute defense of expression in Emerson", en "Spinoza on Freedom of Expression", op. cit., p. 28, nota 25. Sobre la distinción spinozista entre expresión y acción, vid. también William T. Mayton, "Seditious Libel and the Lost Guarantee of a Freedom of Expression”, Columbia Law Review, vol. 84, January, 1984, pp. 109-111.

75 Baruch Spinoza, Tratado Teológico-Politico, Prefacio, op. cit., p. 65.

76 Ibid., XX, p. 410.

77 Ídem.

78 En sentido contrario, José Joaquín Jiménez Sánchez afirma que en la teoría política de Spinoza se articula un Estado politico limitado, que se legitima cuando genera las condiciones necesarias para el cultivo de la razón que se alcanza por medio del ejercicio de las libertades de pensamiento y expresión, vid. "Los fundamentos del estado politico en Spinoza", op. cit., p. 231.

79 Al respecto vid. Francisco Javier Ansuátegui Roig, Orígenes doctrinales de la libertad de expresión, op. cit., p. 217. En el mismo sentido, vid. Lucien Mugnier-Pollet, La philosophie politique de Spinoza, op. cit., p. 166.

80 Como señala Canavan, "Everyman's right to think as he pleases and to say what he thinks must be understood, therefore, in relation to the sovereign's rights", Francis Canavan, Freedom of 
Por esto, la fijación de los límites de la libertad de expresión alcanza significado nuclear en la doctrina política del Tratado Teológico-Político, "Nos incumbe, pues, hasta qué punto se puede y debe conceder a cada uno esa libertad, sin atentar contra la paz del Estado y el derecho de las supremas potestades" ${ }^{81}$, definiéndose el contenido del libre razonar y juzgar "a condición de que se limite exclusivamente a hablar o enseñar y que sólo defienda algo con la simple razón, y no con engaños, iras y odios, ni con ánimo de producir, por la autoridad de su decisión, algo nuevo en el Estado"82. Proceso delimitador predeterminado por aquella opinión que por introducir "algo nuevo en el Estado" atenta contra los fundamentos definidos en el pacto, esto es, aquellas opiniones políticamente injuriosas equivalentes a un acto de sedición, definiéndolas el holandés en función de la naturaleza contractual y obligacional que fundamenta al Estado 83 :

"qué opiniones son sediciosas en el Estado: aquellas cuya existencia suprimen, ipso facto, el pacto por el que cada uno renunció al derecho a obrar según el propio criterio" 84 .

Decayendo, así, el pretendido carácter inocuo de la opinión ${ }^{85}$,

" [...] si alguien está internamente convencido de que la potestad suprema no es autónoma, o de que nadie está obligado a cumplir sus promesas, o de que todo el mundo debe vivir según su propio criterio y otras cosas similares que contradicen abiertamente a dicho pacto, es sedicioso» $\$ 6$.

Y consciente de las implicaciones reduccionistas a que conducen estas doctrinas, Spinoza afirma, en un intento de salvar la libertad, aunque sólo sea a nivel conceptual, que la opinión es sediciosa "Pero no tanto por su juicio y opinión, cuanto por el hecho que dichos juicios implican; puesto que, por el simple hecho de que él piensa tal cosa, rompe la promesa de fidelidad, tácita o manifiestamente hecha a la suprema potestad" 87 . Pacto de fidelidad dirigido a

Expression: Purpose as Limit, op. cit., p. 73.

${ }^{81}$ Baruch Spinoza, Tratado Teológico-Politico, op. cit., XX, p. 410.

82 Ibid., XX, p. 411.

83 En la misma línea interpretativa, señala Peña Echeverría, "En suma, son las que sostienen una doctrina incompatible con las exigencias de constitución y conservación del Estado mismo (no de un régimen determinado)", vid. La filosofía politica de Espinosa, op. cit., p. 384.

${ }^{84}$ Cfr. Baruch Spinoza, Tratado Teológico-Politico, op. cit., XX, p. 413.

85 En sentido contrario se manifiesta Ansuátegui Roig, "Las opiniones no son perseguibles, a no ser que traigan tras de sí, como consecuencia lógica, o como parte integrante de su contenido y significado, determinados actos o hechos [...] Una opinión no puede destruir al Estado, pero esa idea, inocua en sí, provoca conductas que sí pueden socavar los fundamentos políticos de la sociedad", vid. Orígenes doctrinales de la libertad de expresión, op. cit., pp. 218-219.

86 Baruch Spinoza, Tratado Teológico-Politico, op. cit., XX, p. 413.

87 Ídem. También en un intento de conjugar acción y expresión, señala Peña Echeverría, "No se niega, pues, el principio básico de que solamente los actos son susceptibles de sanción por parte de la autoridad; si una creencia es condenable, al ser "sediciosa" es porque va ligada indisolublemente a un acto contrario al Estado", intento forzado, como manifiesta Echeverría a renglón seguido, "De todas maneras, la proclamada inocuidad de las ideas se ve aquí comprometida, al hacerse patente la estrecha vinculación entre la defensa teórica de una posición 
garantizar la seguridad del Estado, y como la historia demuestra que la negación de tal libertad no conduce sino a la destrucción del poder instituido, Spinoza advierte de la ineficacia de las normas que licencian y prohíben la libertad de expresión, "[...] tales leyes son inútiles del todo", porque no sólo conducen al estancamiento del conocimiento y a la negación del progreso, resonando la clásica conexión entre conocimiento-progreso-libertad, "esta libertad es primordial para promover las ciencias y las artes" 88 , sino que también ponen en juego la fidelidad al pacto, esto es, la seguridad del Estado, "Pero supongamos que esta libertad es oprimida y que se logra sujetar a los hombres hasta el punto de que no osen decir palabra sin permiso de las supremas potestades. Nunca se conseguirá con eso que tampoco piensen nada más que lo que ellas quieren. La consecuencia diaria seria, pues, que los hombres pensaran a diario algo distinto de lo que dicen y que, por tanto la fidelidad, imprescindible en el Estado, quedara desvirtuada" 89 . Porque tal desfase entre la libertad de pensamiento y la libertad de expresión sometería a la naturaleza humana al antagonismo más insostenible, y a fomentar un "régimen de disimulo" 90 y a "la adulación y la perfidia que son la fuente del engaño y de la corrupción de los buenos modales", poniéndose en peligro el fin prioritario del modelo politico spinozista, la seguridad del Estado, confirmándose así la centralidad del principio de estabilidad estatal en el discurso de libertad del holandés ${ }^{91}$ :

"Los hombres son por lo general de tal indole que nada soportan con menos paciencia, que el que se tenga por un crimen opiniones que ellos creen verdaderas [...] De ahí que detesten las leyes y se atrevan a todo contra los magistrados, y que no les parezca vergonzoso, sino muy digno, incitar por ese motivo a la sedición y planear cualquier fechoria. Dado, pues, que la naturaleza humana está así constituida, se sigue que las leyes que se dictan acerca de las opiniones [...] no pueden ser defendidas sin gran peligro para el Estado [...] Nadie puede ignorar que todo esto contradice de plano la salvación del Estado"92.

Por todo, Spinoza proclama la libertad de expresión como "un mal necesario" en el Estado, por temor a que en otro caso se frustre el presupuesto ontológico del sistema político que dibuja, su seguridad. Su objetivo no es proclamar un principio universal de libertad individual, no es proclamar la libertad del

y su realización práctica. Da la impresión de que Espinosa argumenta de cara al lector poderoso", vid. La filosofía politica de Espinosa, op. cit., p. 384.

88 Baruch Spinoza, Tratado Teológico-Politico, op. cit., XX, p. 414. Al respecto, vid. Francisco Javier Ansuátegui Roig, "Libertad de conciencia y de expresión en Baruch de Spinoza", en F. J. Ansuátegui Roig, J. M. Rodríguez Uribes, G. Peces-Barba y E. Fernández García (coords.), Historia de los Derechos Fundamentales, vol. 1, 1998, p. 670.

89 Ibid., pp. 414-415.

90 Cfr. Francisco Javier Peña Echeverria, La filosofía politica de Espinosa, op. cit., p. 385.

91 "[...] hay otras consecuencias mucho más detestables, derivadas de la restricción de la libertad de pensamiento y expresión. La gravedad de dichas consecuencias [...] viene determinada [...] por las importantes consecuencias en relación con la estabilidad del Estado", Francisco Javier Ansuátegui Roig, Orígenes doctrinales de la libertad de expresión, op. cit., p. 221.

92 Baruch Spinoza, Tratado Teológico-Politico, op. cit., XX, pp. 415 y 420. 
individuo per se, es proclamar la libertad para la Democracia, no la Democracia para la libertad. La finalidad del Estado es buscar la seguridad, no tanto individual sino colectiva, realizable en el modelo de Estado absoluto-democrático que diseña, porque la libertad no se conquista frente al Estado, sino en el Estado $^{93}$. Por esto, en la doctrina política diseñada por el holandés, la libertad de expresión no es un límite para el Estado, antes al contrario, el Estado es el límite de la libertad de expresión, límite único y absoluto, por esto no tolera la opinión sediciosa, manifestación de la diversidad humana, y de ahí, que, aunque Spinoza sea consciente del carácter plural y heterogéneo que de la naturaleza humana refleja la libertad de expresión, pretenda reconducirla a la unidad a través del pacto. Sin embargo, la pretensión spinozista de unidad es un proyecto inviable, el pacto es conductor de la pluralidad, no conductor a la unidad, el concepto de unidad repele a la naturaleza humana, de ahí que cuando Spinoza acepta tal concesión el núcleo del argumento a favor de la libertad de expresión decae ${ }^{94}$.

En fin, Spinoza limita el ejercicio de la libertad de expresión en aras del respeto al origen contractual del sistema y fija el límite en las expresiones sediciosas $^{95}$. Así, el holandés, presupone el carácter infalible del Estado racionalista-democrático que defiende, porque ya que prima la razón (de Estado) no es posible que haga cosas contrarias a ésta, y de nuevo, el argumento de la libertad cede frente al de la seguridad, "Muy rara vez puede acontecer que las supremas potestades manden cosas muy absurdas [...] tales absurdos son menos de temer en un Estado democrático; es casi imposible [...] Lo impide, además, su mismo fundamento y su fin, el cual no es otro que evitar los absurdos del apetito y mantener a los hombres dentro de los limites de la razón, a fin de que vivan en paz y concordia» ${ }^{96}$. De esto a afirmar el carácter infalible del gobierno democrático solo hay un paso ${ }^{97}$.

Terreno resbaladizo este de la infalibilidad, porque, como la historia nos enseña, el mayor error a que puede conducir el gobierno de la mayoría es asfixiar a la minoria hasta tiranizarla, provocando su propia destrucción ${ }^{98}$. Terreno

93 En este sentido, vid. Francisco Javier Peña Echeverría, La filosofía politica de Espinosa, op. cit., p. 274. En sentido contrario, Atilano Dominguez defiende un concepto democrático más arraigado en la concepción spinozista, "Spinoza [...] no se inscribe en la línea Hobbes-RousseauHegel, tachada de absolutismo estatal y conservador, sino en la linea Maquiavelo-SpinozaFeuerbach-Marx, calificada de democracia popular y revolucionaria", vid. "Spinoza", op. cit., pp. 311-312.

94 Al respecto, vid. Lewis Samuel Feuer, Spinoza and the Rise of Liberalism, op. cit., p. 115.

95 Vid. Leonard W. Levy, Emergence of a Free Press, op. cit., pp. 89-91. Como pone de relieve Pedro Bravo Gala al concluir las escasas lineas que dedica a la doctrina spinozista en su edición de la Carta sobre la Tolerancia de John Locke, "En resumen, Spinoza defiende la libertad de pensamiento como condición esencial de la propia vida política [...] de dicha libertad quedan excluidas únicamente las opiniones "sediciosas", es decir, aquellas que suponen la negación de la esencia del contrato", John Locke, Carta sobre la tolerancia, op. cit., p. xxx.

96 Baruch Spinoza, Tratado Teológico-Político, op. cit., XVI, p. 339.

97 En este sentido, señala Smith, "At one point he comes dangerously close to maintaining that the will of the majority is infallible. Since questions of right and wrong only come to light in society, the sovereign alone has the authority to establish the rules of justice. Justice is no more but also no less than what the sovereign says it is", Steven B. Smith, "Spinoza's Democratic Turn: Chapter 16 of the 'Theological-Political Treatise", op. cit., pp. 359 y ss.

98 Ciertamente, el gobierno democrático se había considerado tradicionalmente contrario al derecho de las minorias y a la libertad individual, con acierto se recordaba en El Federalista, " [...] 
resbaladizo en el que parece deslizarse el discurso político del holandés, pues, como consecuencia del carácter infalible que del Estado defiende -carácter infalible que deviene sin duda del pesimismo antropológico que define al estado de naturaleza spinozista como un mal no deseable, al que no puede volverse, la ausencia de razón en el estado de naturaleza lo impide, de ahí el carácter irreversible del pacto-, Spinoza no arbitra ningún mecanismo que permita revocar al gobernante, reflejando tal "pesimismo ante el cambio" que aboga por el estatismo político más absoluto:

"La forma de cada Estado debe ser necesariamente mantenida y no puede ser cambiada sin peligro de su ruina" 99 .

Pesimismo ante el cambio que vuelve a manifestarse en el Tractatus Politicus, cuando Spinoza interpreta las doctrinas maquiavélicas sobre la deposición del tirano, reflejándose, una vez más, hasta qué punto el pesimismo antropológico que revela el presupuesto filosófico de la necesidad influye en la doctrina política del holandés,

" [...] cuán imprudentemente intentan muchos quitar de en medio a un tirano, cuando no se pueden suprimir las causas por las que el principe es tirano" 100 .

Pesimismo antropológico ante el cambio que encadena para siempre el concepto de libertad spinozista - aunque escasa doctrina se haya percatado de su relevancia-101, porque si algo caracteriza al gobierno democrático es el concepto de continua revolución interior, el gobernante de hoy puede ser el tirano del mañana, porque si el pacto es para la libertad, el poder tiránico es revocado, pero si la libertad es para el pacto y el poder derivado del mismo, la libertad está a su servicio, la libertad se torna esclavitud. Aunque realmente, el pesimismo antropológico ante el cambio no es más que consecuencia del concepto estático de libertad a que conduce la teoría política de Spinoza, sometida a la necesidad de un Estado que no puede ser renovado porque no hay lugar a la revolución,

concluir que una democracia pura, por la que entiendo una sociedad integrada por un reducido número de ciudadanos, que se reúnen y administran personalmente el gobierno, no puede evitar los peligros del espíritu sectario. En casi todos los casos, la mayoría sentiría un interés o una pasión comunes; la misma forma de gobierno producirá una comunicación y un acuerdo constantes; y nada podrá atajar las circunstancias que incitan a sacrificar al partido más débil o a algún sujeto odiado. Por eso estas democracias han sido siempre incompatibles con la seguridad personal y los derechos de propiedad", vid. A. Hamilton, J. Madison y J. Jay, El Federalista, Fondo de Cultura Económica, México, 5ª reimpresión, 1994, Madison, X, p. 39.

99 Baruch Spinoza, Tratado Teológico-Politico, op. cit., XVIII, p. 391.

100 Baruch Spinoza, Tratado Político, op. cit., p. 121.

101 De la literatura consultada, Peña Echeverría parece haber comprendido la verdadera quiebra de la doctrina política del holandés, "Dados los planteamientos de la filosofía política de Espinosa, comprensiva y necesarista, el problema del derecho a la rebelión, tan debatido en la Europa del siglo XVI, queda, igual que en Hobbes, vacío de contenido. Los procesos políticos están presididos por una dinámica necesaria y, como sabemos, Espinosa identifica derecho y poder. La obediencia al Poder no es un deber moral, sino un requisito necesario para garantizar la propia seguridad", vid. La filosofía politica de Espinosa, op. cit., p. 407. 
negándose así el concepto de libertad ${ }^{102}$. Porque el devenir histórico político nos enseña que no hay libertad sin revolución, produciéndose esa especie de "simbiosis dinámica" entre los conceptos de libertad y revolución, porque no hay nada más dinámico y progresivo que la libertad, y no hay nada más dinámico que la conquista de la libertad, interna y externa, personal y política, individual y colectiva. En fin, la quiebra del concepto histórico en la teoría política de Spinoza no es sino consecuencia del presupuesto que vertebra su teorización, la libertad como necesidad, y no hay nada más estático que lo necesario, porque frente a la necesidad, ¿dónde queda el cambio y por tanto la libertad? ${ }^{103}$.

Por todo esto, y por último, el discurso spinozista en defensa de la libertad de expresión se arbitra más como instrumento que tiende a garantizar la seguridad colectiva que como mecanismo de consagración de la autonomía y autorrealización individual. Disentimos por tanto del forzado intento que ha ofrecido B. Bubacz por encuadrar el discurso spinozista a favor de la libertad de expresión en el llamado "constitutive free speech model"104, alejándolo así del clásico argumento utilitarista que ha venido caracterizando la defensa del "marketplace model", porque, aunque es cierto que la defensa spinozista de la libertad de expresión no puede encuadrarse fácilmente en el modelo del Mercado de las Ideas, tampoco es menos cierto que su argumentación no sea instrumentalista, canalizada como medio para asegurar la paz y la seguridad del Estado, olvidando quizás Bubacz las implicaciones de su teoría política, dominada por el principio de la necesidad antropológica y de la negación del individuo al margen del Estado, negación, al fin y al cabo de la libertad humana ${ }^{105}$.

102 Al respecto, vid. Francisco Javier Peña Echeverría, La filosofía politica de Espinosa, op. cit., p. 410. Sobre el concepto de la historia en Spinoza, entre otros, vid. Javier Peña, "Historia $e$ historicidad en Espinosa", Cuadernos de Investigación Histórica, vol. 4, 1980, pp. 53-65; Alexandre Matheron, Individu et communatuté chez Spinoza, Ed. Du Minuit, París, 1969, pp. 356359. Por su parte, J. Préposiet defiende incluso una "dialéctica histórica" en la teorización spinozista, vid. Spinoza et la liberté des hommes, Gallimard, París, 1967, pp. 32-33 y 111.

103 Como concluye Peña Echeverría, "En realidad, lo que aquí está en juego es mucho más que el problema del cambio politico. Al fin y al cabo, la resistencia de Espinosa a considerar temáticamente este problema es simplemente un sintoma. Síntoma de que la concepción espinosista se detiene (al menos explicitamente en lo dado). De que no ha sospechado que sea posible romper un orden que aparenta ser natural, pero que en realidad es histórico, y corresponde por tanto, no a la legalidad inmutable de la Naturaleza, sino a las reglas socialmente construidas de la Ciudad que, por consiguiente podrian cambiarse y conducirnos a una forma de existencia que aún no nos es posible sino esbozar", vid. La filosofía política de Espinosa, op. cit., p. 418.

104 "The conventional explanation of why freedom of speech is important is Mill's theory that truth is most likely to emerge from a 'marketplace' of ideas freely exchanged and debated". Mill's arguments are primarily instrumental [...] However, the philosophical tradition of free speech argumentation is far richer than Mill's instrumentalism [...] The current discussion examines two constitutive arguments for free expression presented by the Seventeenth Century Dutch philosopher Baruch Spinoza, the argument from human nature and personal merit", Bruce Bubacz, "Constitutive Free Speech Justifications: Spinoza's Arguments form Human Nature and Personal Merit”, op. cit., pp. 146-147.

105 En este sentido señala Mossé-Bastide, "[...] para Espinosa, concebirse como uno de los eslabones de una cadena ininterrumpida de causas a la vez causadas y causantes, produce la embriaguez de fusionarse con la naturaleza, de participar en la necesidad universal que no es sino otro nombre de la libertad de Dios. Pero esta participación es una anulación del sujeto, que renuncia a su responsabilidad personal y a su dignidad humana", Rose-Marie Mossé-Bastide, La 
De ahí que no podamos calificar al solitario de la Haya de autor "liberal", al proyectar un concepto de "libertad positiva" sólo realizable en el Estado106, anulándose así los conceptos de la individualidad y de la libertad ${ }^{107}$, confirmándose, en fin, los límites que sesgan la doctrina política del holandés, necesitada del Estado como instrumento de realización de la libertad ${ }^{108}$. De ahí que se aproxime la teorización política spinozista a la hegeliana ${ }^{109}$. Desconocimiento de la autonomía individual que impide defender un auténtico sistema de libertades en la teorización política de Spinoza ${ }^{110}$, articulándose el discurso en defensa de la libertad de expresión en el ámbito relacional del individuo, concibiéndola como un mecanismo para la pervivencia del Estado como consecuencia de su carácter absoluto- ${ }^{111}$ y no como vehículo que permite la satisfacción de la dimensión racional de la autonomía y libertad humanas ${ }^{112}$. Y es que el proyecto de racionalización colectiva que predica la doctrina política del holandés conduce, paradójicamente, a la alienación del concepto individual, sólo alcanzable en el todo, confirmándose que para Spinoza la libertad no es más que

liberté, $2^{\mathrm{a}}$ ed., Presses Universitaires de France, Paris, 1969, p. 22, recogido por Peña Echeverría en La Filosofía politica de Espinosa, op. cit., p. 358.

106 Para un intento de dibujar un "concepto integrador" de libertad positiva en el discurso sobre la libertad de expresión spinozista, vid. Edward I. Pitts, "Spinoza on Freedom of Expression", op. cit., pp. 26-35.

107 Al respecto, señala Peña Echeverria, "Y, sin embargo, debemos insistir en que no se trata de una defensa "humanista". No se apela tanto a "los sentimientos comunes a todos los hombres", a los preceptos morales, a la dignidad humana, como a la necesidad lógica de la libertad de pensamiento (aunque se hable también de su conveniencia práctica). Y lo que se trata de garantizar, al menos explícitamente, no es tanto una aspiración individual como las exigencias y objetivos de la sociedad politica", Francisco Javier Peña Echeverría, La filosofía politica de Spinosa, op. cit., p. 387.

108 Ibid., p. 38.

109 «[...] en modo alguno podría identificarse a Espinosa con una concepción política en la que los individuos, y, en general, lo que Hegel llamará "sociedad civil" son entidades autónomas, preexistentes y prioritarias respecto a la estructura politica estatal, concebida como instrumento de intereses a fin de cuentas siempre privados [...] El proyecto político de Espinosa apunta, por el contrario, a una comunidad democrática en la que la multitudo comparte el poder, y por ello la libertad, es decir, la capacidad de autodeterminación, y en la que al identificarse el sujeto y el objeto, no tiene sentido ya la consideración separada del individuo y el Estado", Francisco Javier Peña Echeverria, ibid., p. 15.

110 Cfr. Roland Maspetiol, “L’Etat et le Droit selon Spinoza”, op. cit., pp. 159-160 y 173-174.

111 En este sentido, vid. Francisco Javier Peña Echeverría, La filosofía politica de Espinosa, op. cit., pp. 271-274. El carácter absoluto del Estado a que conduce la construcción spinozista no puede siquiera soslayarse a través de un intento de conceptualizar la libertad como "un limite de naturaleza ética que puede ser eficaz en el plano político", Guido Fassò, Historia de la filosofía del derecho, vol. II, La Edad Moderna, trad. de J. F. Lorca Navarrete, Ediciones Pirámide, Madrid, 1981, p. 120.

112 Para una crítica similar a la concepción liberal del pensamiento spinozista, vid. Roland Maspetiol, “L'Etat et le Droit selon Spinoza", op. cit., pp. 159-160 y 173-174. Para una visión más liberal y democrática de la filosofia de Spinoza, vid. Robert J. McShea, The Political Philosophy of Spinoza, op. cit., p. 199; Atilano Dominguez, "Libertad y democracia en la filosofía politica de Spinoza", op. cit., p. 156. Y para un intento de conjugar las diferentes interpretaciones del pensamiento spinozista, vid. Francisco Javier Ansuátegui Roig, Orígenes doctrinales de la libertad de expresión, op. cit., pp. 225-226. 
pura ilusión ${ }^{113}$. De ahí que, como se analiza a continuación, el restrictivo discurso spinozista no tenga nada que hacer frente a la defensa de la libertad de expresión que ofreció John Milton en la Areopagitica, predeterminada por un concepto de libertad dinámico, predicable del individuo frente al poder, anticipando así el concepto moderno de libertad que consagraría dos siglos más tarde John Stuart Mill en On Liberty.

\section{LA SUPERACIÓN DEL DISCURSO SPINOZISTA EN EL ENSAYO FUNDACIONAL DE LA CONCEPCIÓN MODERNA DE LA LIBERTAD DE EXPRESIÓN: LA AREOPAGITICA DE JON MILTON}

Aunque en la teoría politica de Baruch Spinoza ocupa un lugar destacado la defensa de la libertad de pensamiento y expresión, hasta el punto de que constituye en gran medida el fundamento del poder político y del Estado, sin embargo, su defensa de la libertad de expresión no alcanza parangón con la formulada unos años antes en el ensayo fundacional del libre debate, el discurso que el poeta republicano John Milton (1608-1674) dirigió al Parlamento inglés el 24 de noviembre de 1644 para justificar la extinción del férreo sistema de censura previa vigente en la Inglaterra de mediados del siglo XVII ${ }^{114}$, con el singular título de Areopagitica, A Speech for the Liberty of Unlicensed Printing to the Parlament of England ${ }^{115}$, génesis del argumento más esgrimido en el moderno proceso de conceptualización de la libertad de expresión, esto es, el libre encuentro de mentes y opiniones como medio para el enfrentamiento abierto entre la verdad y el error, y, en última instancia, para alcanzar la verdad y la libertad ${ }^{116}$, siendo el primer escrito de la modernidad que reivindica la libertad de expresión como derecho personal no sujeto a una determinada connotación religiosa, política o filosófica, ni circunscrito al ámbito parlamentario, idea poco

113 Al respecto, señala Peña Echeverría, "Espinosa es consciente de que su propia visión de la realidad implica una férrea dependencia del sujeto humano con respecto al orden causal global. Pero el libre arbitrio, en el que los filósofos hacen radicar habitualmente la dignidad del hombre, es para él solamente una ilusión", en La filosofía política de Espinosa, op. cit., p. 81.

114 Sobre el restrictivo sistema de censura previa vigente en la Inglaterra del siglo XVII, vid. mi estudio previo y bibliografia alli citada, Maria Nieves Saldaña, "A Legacy of Suppression»: Del control de la información y opinión en la Inglaterra de los siglos XVI y XVII", Derecho y Conocimiento. Anuario Jurídico sobre la Sociedad de la Información y del Conocimiento, vol. 2, pp. 175-211.

115 Según el conocido Catálogo de George Thomason, la Areopagitica fue editada sin licencia ni registro de impresión, con el título y el nombre de Milton, el 24 de noviembre de 1644, al respecto vid. J. M. French (ed.), The Life Records of John Milton, 5 vols., New York, Gordian Press, 1966, vol. II, pp. 113-114. En el presente trabajo se utiliza la edición publicada en D. M. Wolfe (Gen. Edit.), Complete Prose Works of John Milton, 8 vols., Yale University Press, New Haven and London, 1953-1982, vol. II (1643-1648), Ernest Sirluck (ed.), pp. 485-570. Para una edición bilingüe inglés-español, vid. John Milton. Areopagítica, estudio preliminar de M. Carrillo, traducción, edición y notas de J. Curbert, Madrid, Tecnos, 2011.

116 "Though all the windes of doctrin were let loose to play upon the earth, so Truth be in the field, we do injuriously by licencing and prohibiting to misdoubt her estrenght. Let her and Falshood grapple; who ever knew Truth put to the wors, in a free and open encounter?", John Milton, Areopagitica, Complete Prose Works of John Milton, op. cit., vol. II, p. 561. 
corriente, incluso, en el siglo XVIII'17.

En efecto, aunque existen algunas conexiones entre las doctrinas de ambos autores $^{118}$, sin embargo, la concepción que ofrece Milton en la Areopagitica está impregnada de su teoría política de corte contractualista en la que el pacto tiene como finalidad garantizar la libertad individual y no la seguridad del Estado, por esto si el gobernante no respeta el presupuesto contractual debe ser revocado, constituyendo la revocación del pacto elemento estructural básico del modelo de Estado que Milton defiende ${ }^{119}$. Sin duda, el discurso areopagítico frente a la censura está imbuido de la concepción contractual del poder político a que responden los escritos politicos de Milton, especialmente su tratado en defensa del tiranicidio, The Tenure of Kings and Magistrates (1649) ${ }^{120}$, en el que Milton sienta las bases precursoras de la teoría liberal del contrato social, y su defensa de la república cromweliana, A Defence of The People of England (1651)121. Origen pactista sobre el que fundamenta Milton la revocación del poder absoluto del Monarca inglés, apelando a la libertad natural, al llamado "birthright", para justificar la naturaleza fiduciaria del poder que el pueblo deposita en los gobernantes, el derecho de resistencia, el derecho del pueblo a deponer el gobierno tiránico que atenta a la paz y al bien común, e, incluso, el principio

117 De los numerosos estudios sobre el ensayo miltoniano, entre los más recientes vid. Erik L. Johnson, "Life Beyond Life": Reading Milton's Areopagitica thorough Enlightenment Vitalism", Eighteenth Century Studies, vol. 49, núm. 3, 2016, pp. 353-370; Jeffrey P. Beck, "The Singularity of Areopagitica. A Quantitative Analysis of John Milton's Prose Works", Historical Methods: A Journal of Quantitative and Interdisciplinary History, vol. 48, núm. 3, 2015, pp. 174-184; Ben LaBreche, "Milton and the Limits of Pluralism", Milton Studies, núm. 54, 2012, pp. 139-160; Warren Chernaik, "Areopagitica: "The Known Rules of Antient Libertie", The European Legacy: Toward New Paradigm, vol. 17, n. 3, 2012, pp. 317-331; Regina M. Schwartz, "Truth, Free Speech, and the Legacy of John Milton's Areopagitica", Teoria, vol. 32, n. 1, 2012, pp. 47-58; Isaac M. Morehouse, "Areopagitica: Milton's Influence on Classical and Modern Political and Economic Thought", Libertarian Papers, vol. 1, article núm. 38, 2009, pp. 1-14; Paul M. Dowling, “Civil Liberty and Philosophic Liberty in John Milton's 'Areopagitica", Interpretation-A Journal of Political Philosophy, vol. 33, n. 3, 2006, pp. 281-294.

118 Como señala Francisco Javier Ansuátegui Roig, "podemos observar que [Spinoza] comparte con Milton la denuncia de los argumentos de autoridad en el ámbito de las creencias religiosas, la afirmación de que la conciencia constituye un ámbito en el que no cabe la imposición sino la exhortación, el convencimiento de la inutilidad práctica de los diversos mecanismos de censura y los funestos efectos de dichas técnicas para la ciencia y el avance del saber", vid. "Libertad de conciencia y de expresión en Baruch Spinoza", en G. Peces-Barba Martínez [et al.], Historia de los Derechos Fundamentales. Tomo I: Tránsito a la Modernidad, siglos XVI y XVII, Dykinson, Madrid, 2003, pp. 639-681, especialmente p. 677.

119 Como ha señalado Gregorio Peces-Barba Martínez, "El estado de naturaleza se superará para un mejor y más decisivo goce de los derechos naturales, y se pasará por medio del contrato social - pactum unionis - al estado de sociedad. En éste, los ciudadanos decidirán organizar al poder - pactum subjectionis-, dando como finalidad fundamental a éste la defensa y protección de los derechos naturales [...] Si la justificación del poder es esta defensa de los derechos fundamentales y si el pactum subjectionis no es irreversible como en Hobbes, manteniendo el pueblo la soberanía, el incumplimiento de las obligaciones del poder permite la revocación de los gobernantes, siendo uno de los derechos fundamentales el derecho a la insurrección contra el poder injusto", vid. Tránsito a la Modernidad y Derechos Fundamentales, Editorial Mezquita, Madrid, 1982, p. 166.

120 John Milton, The Tenure of Kings and Magistrates, en Complete Prose Works of John Milton, op. cit., vol. III (1648-1649), pp. 190-258.

121 John Milton, A Defence of the People of England, en Complete Prose Works of John Milton, op. cit., vol. IV, Part I (1650-1655), pp. 301-537. 
miltoniano más revolucionario, esa especie de "republicanismo transconstitucional" que reconoce el derecho del pueblo a revocar el poder conferido no sólo cuando se ejerce tiránicamente, sino en cualquier momento en el que accione su derecho natural a gobernarse como quiera ${ }^{122}$. Y es que el pacto diseñado por Milton es, antes que nada, un pacto de libertad, garantía de los derechos inalienables preexistentes a toda organización política, de ahí la naturaleza garantista del ente surgido del pacto, el Estado, que se legitima por el respeto de la igual libertad, y de ahí, también, que su intervención restringiendo los derechos y libertades suponga la rescisión del pacto ${ }^{123}$, confirmándose que la libertad es la primera preocupación en la teoria política del poeta revolucionario ${ }^{124}$.

Doctrinas contractualistas de racionalización y limitación del poder que, opuestas a las teorias absolutistas de Hobbes, sitúan a Milton en la cultura jurídica de lo que podríamos llamar la "trust theory", esa suerte de naturaleza fiduciaria, de mandato y confianza, que preside, limita y garantiza la relación contractual entre gobernantes y gobernados, basada en el consentimiento del pueblo soberano de carácter revocable. Criterio definitorio de la obligación contractual que alcanzaria definitiva plasmación en los panfletos y ensayos que adoctrinaron al proceso revolucionario de 1688, resonando los ecos de las doctrinas politicas miltonianas en los escritos de la posterior ideología republicana y Whig inglesa y en la teoria contractualista del fundador del liberalismo político, el mismo John Locke. Quizás por esto no sorprenda las evidentes conexiones existentes entre la "trust theory" miltoniana y lockeana, reflejándose en la teorización que ambos autores ofrecen del derecho de resistencia ${ }^{125}$.

De ahí la concepción miltoniana de la libertad como derecho derivado del nacimiento, como "birthright", concepto al que apela la conciencia constitucional inglesa a principios del siglo XVII para defender la supremacía del Common Law y la limitación de la prerrogativa regia por el órgano parlamentario. Concepto al que apela el célebre Edward Coke, representando el Common Law en términos de "birthright" y de "inheritance" del súbdito inglés, la mejor garantía con que cuenta para defender no sólo sus tierras sino también "his body, fame and life also"126.

122 Para un análisis detallado sobre el alcance de la teoría política miltoniana y su repercusión e influencia vid. mis estudios previos y bibliografia alli citada, Maria Nieves Saldaña, "El Poeta de la Revolución Puritana: Teoría Politica de John Milton", Historia Constitucional (Revista Electrónica), núm. 2, junio, 2001, pp. 161-200; y "Teoria Politica de John Milton: presencia e influencia en la América colonial y revolucionaria", Historia Constitucional, (Revista Electrónica), núm. 4, junio, 2003, pp. 235-269.

123 En este sentido, vid. Victoria Kahn, "The Metaphorical Contract in Milton's Tenure of Kings and Magistrates", en David Armitage, Armand Himy y Quentin Skinner (eds.), Milton and Republicanism, Cambridge University Press, Cambridge, 1995, pp. 83-105, especialmente p. 96.

124 Al respecto vid. William A. Dunning, A History of Political Theories from Luther to Montesquieu, Macmillan, London, 1928, p. 246.

125 Como señala Martin Dzelzainis, "For not the least of the similarities between Locke and Milton is their adoption of a stoic perspective which allows them to assert, with the minimum of qualification, the right of the people, and even of individuals, to resist their tyrannical rulers", vid. Introducción a John Milton. Political Writings, Cambridge University Press, New York, 1991, p. xxv.

126 Edward Coke, Preface to Reports, pt 5, 1605, impreso en Caudrey's Case in Edward Coke, 1826, p. iv, reproducido en Catherine D. Bowen, The Lion and the Throne: The Life and Times of Sir Edward Coke, Hamish HaMilton, London, 1957, p. 439. 
Concepto que de igual manera constituye presupuesto fundacional de la doctrina politica que John Milton defiende en The Tenure of Kings and Magistrates y en $A$ Defence of the People of England para legitimar la deposición del tirano en 1649, el mejor don que puede recibir la persona al nacer, que de suyo le pertenece y que, como Milton proclamó en A Defence of The People of England, no puede ceder "to any Caesar", sin atentar a su libre naturaleza ${ }^{127}$. Y es también el concepto al que apela el londinense ante el Parlamento de Inglaterra, reivindicando la libertad de expresión como derecho personal no sujeto a una determinada connotación política, filosófica o religiosa, ni circunscrito al ámbito parlamentario, idea poco corriente incluso en el siglo XVIII ${ }^{128}$.

En efecto, la Areopagitica constituye la primera defensa en sentido moderno de la libertad de expresión como libertad personal y garantía de la autonomía individual, porque Milton comprendió que nuestra naturaleza de seres racionales está tan intimamente relacionada con la palabra y otros sistemas de comunicación que entendió mejor que ningún otro pensador de su tiempo que la limitación tiránica de tales medios de comunicación provoca una distorsión de nuestra integridad moral y, en definitiva, el menoscabo de la libertad, de ahí que Milton proclame ante el Parlamento en clave eternamente universal:

"If it be desir'd to know the immediate cause of all this free writing and free speaking [... ] it is the liberty, Lords and Commons, which your own valorous and happy counsels have purchast us, liberty which is the nurse of all great wits [...] Although I dispraise not the defence of just immunities, yet love my peace better, if that were all. Give me de liberty to know, to utter, and to argue freely according to conscience above all liberties» 129 .

Pero además, según el discurso areopagítico el libre debate no sólo contribuye a la autorrealización individual sino también al buen gobierno, pues lo que distingue a un buen gobierno es la capacidad para reconocer y corregir errores, de ahí la relevancia del libre debate y de la libertad de crítica implementada desde las esferas ciudadanas:

"This I know, that errors in a good government and in a bad are equally almost incident; for what Magistrate may not be mis-inform'd, and much the sooner, if liberty of Printing be reduc't into the power of a few; but to redresse willingly and speedily what hath bin err'd, and in highest authority to esteem a plain advertisement more then others have done a sumptuous bribe, is a virtue (honour'd Lords and Commons) answerable to Your highest actions, and

127 "Our freedom belongs not to Caesar, but is rather a gift from God himself given us at birth, and to surrender it to any Caesar, when we did not receive it of him, would be an act of shame most unworthy of man's origin", John Milton, A Defence of the People of England, en Complete Prose Works of John Milton, op. cit., vol. IV, Part I, p. 376.

128 Como señala Levy "Milton in 1643 referred to "freedom of speech" in the sense of a personal rather than a parliamentarian's right. In the eighteenth century this usage, although more common, was still unusual before 1776", Leonard W. Levy, Emergence of a Free Press, op. cit., p. 4.

129 John Milton, Areopagitica, en Complete Prose Works of John Milton, op. cit., vol. II. pp. 559560. 
whereof none can participat but greatest and wisest men» ${ }^{130}$.

Dinamismo individual y colectivo, privado y público, que refleja el epigrafe introductorio que en boca de Las Suplicantes de Euripides abre las puertas de la Areopagitica ${ }^{131}$, proclamando el discurso areopagitico desde el frontispicio que la libertad de crítica reconocida al ciudadano contribuye tanto al proceso de aprendizaje individual como al progreso colectivo y social:

"This is true Liberty when free born men

Having to advise the public, may speak free,

Which he who can, and will, deserves high praise;

Who neither can, nor will, may hold his peace:

What can be juster in a State than this?»132.

En consecuencia, el ejercicio libre y autónomo de la libertad de expresión se proyecta en la autonomía del pueblo, concretada en la libre elección de los gobernantes y en el derecho al cambio social y politico, conectando Milton la dimensión individual y colectiva de la libertad de expresión, y justificando, por tanto, la extirpación de todo tipo de control, manifestándose así en el ensayo fundacional del libre debate el dinamismo que caracteriza a la teoría politica miltoniana y que constituye presupuesto fundacional de la Areopagitica. De ahí que la defensa de la libertad de expresión que trasciende la Areopagitica supere el principal argumento que doctrinal y jurisprudencialmente se ha atribuido al ensayo miltoniano, instrumentalizándose la búsqueda de la verdad en aras del sustrato axiológico que informa al discurso areopagítico, la potenciación de la autorrealización individual como presupuesto de canalización del control político y del progreso colectivo, consagración que requiere de un proceso continuo de elección racional en el que juega un papel fundamental el grado de autonomía de que goza el individuo a nivel institucional, que, garantizada, potencia la existencia de seres racionales que eligen libremente y contribuyen en su conjunto al progreso colectivo, de ahí el rechazo miltoniano de toda censura o licencia previa $^{133}$.

Por tanto, la Areopagitica es mucho más que un mero alegato a favor de la libertad de prensa, pues en la defensa miltoniana de la libertad de expresión se

130 John Milton, Areopagitica, en Complete Prose Works of John Milton, op. cit., vol. II. p. 570.

131 Sobre el rótulo introductorio de la Areopagitica y su significación para la interpretación del ensayo miltoniano, vid. Paul M. Dowling y David Davies, "Shrewd Books, with Dangerous Frontispieces': Areopagitica's Motto”, Milton Quarterly, vol. 20, 1986, pp. 33-37; vid. también, Annabel Patterson, Censorship and Interpretation: The Conditions of Writings and Reading in Early Modern England, University of Wisconsin Press, Madison, 1984, p. 115.

132 Para una reproducción de la página frontal de la Areopagitica, incluyendo la versión griega y la traducción inglesa del citado epígrafe realizada por Milton, vid. The Complete Prose Works of John Milton, op. cit., vol. II, p. 485.

133 Para un análisis más detallado vid. mis estudios previos y bibliografía allí citada, María Nieves Saldaña, "En defensa de la libertad de prensa: La Areopagitica de John Milton", Revista de Estudios Políticos, núm. 125, 2004, pp. 277-324; y "Libertad de prensa y energía política en la Areopagítica de John Milton", Revista Internacional de Pensamiento Político, vol. 3, 2007, pp. 211 235. 
entrelazan tanto los clásicos principios del humanismo racionalista, esto es, la libre autorrealización individual a través del conocimiento y del ejercicio de la razón, autorrealización racional que visiona al individuo como sujeto moralmente autónomo capaz de discernir entre el bien y el mal, sujeto dinámico sometido al continuo devenir que implementa la incesante conquista de la verdad y de la libertad, como el emergente énfasis que la doctrina republicana hizo recaer sobre el humanismo cívico de corte maquiavélico, esto es, la necesaria conjugación de la dimensión individual y colectiva de la libertad, la inevitable integración de la libertad individual en el dinamismo de la igualitaria realización pública, de ahí que no pueda sostenerse una sociedad enérgica y cambiante sin un afianzado compromiso en el libre debate, por esto y por encima de todo, Milton defendió en el ensayo areopagítico una concepción abierta y dinámica de la libertad de expresión, vehículo de potenciación y canalización de la energía política y social y de consecución del progreso colectivo. En consecuencia, la defensa de la libertad de prensa que Milton articula en el ensayo areopagitico integra un concepto de libertad plural, individual y colectivo, privado y público, abierto y dinámico, en la medida en que para la concepción miltoniana el ejercicio libre y racional de la libertad de expresión es fundamento de la energía política y de la consecución del progreso social, constituyendo así el dinamismo político y social postulado fundamental de la argumentación que Milton sostiene en la Areopagitica. Interconectándose así el concepto de libertad que Milton defiende en la Areopagitica con el sustrato axiológico que irradia su teoría política, esto es, la exigencia de una sociedad dinámica y vibrante, de ahí que Milton haya sido considerado uno de los precursores de la "sociedad abierta"134.

Por todo, no sorprende la extraordinaria y centenaria influencia ejercida por las avanzadas doctrinas de la Areopagitica, alcanzando ya repercusión en el discurso a favor de la tolerancia religiosa imperante en la etapa puritana $\mathrm{y}$, especialmente, en los escritores radicales del periodo republicano, resonando en las controversias religiosas tras la Restauración, extendiéndose la influencia de la Areopagitica desde su aparición en 1644 hasta la muerte del mismo Milton en 1674135. Incluso, después de su muerte, las doctrinas areopagiticas están presentes en los escritos de Whigs defensores de la libertad de prensa de finales del siglo XVII y principios del siglo XVIII y, paradigmáticamente, en las doctrinas neorepublicanas que John Trenchard y Thomas Gordon defendieron en su célebre ensayo sobre la libertad de expresión incluido en las Cato's Letters, Of Freedom of Speech: That the Same is Inseparable from Publick Liberty ${ }^{136}$.

134 Roy V. Leeper señala al respecto, "Milton is generally perceived as one of the major architects of an open society. The Areopagitica is primarily responsible for this reputation", vid. "Estrage Bedfellows: John Milton and Karl Marx on Censorship", Free Speech Yearbook, vol. 34, 1996, pp. 24-40, especialmente p. 24.

135 Para un análisis más detallado vid. mi estudio previo y bibliografía allí citada, Maria Nieves Saldaña, "El ensayo fundacional de la libertad de prensa en la tradición constitucional euroatlántica: la Areopagitica de John Milton. Repercusión e influencia en la Inglaterra de su tiempo, 1644-1674", Giornale di Storia Costituzionale, núm. 25, I semestre, 2013, pp. 181-200.

136 Vid. Cato's Letters: Or Essays on Liberty, Civil and Religious, and Other Important Subjects, especialmente núm. 15, 4 de febrero de 1720, "Of Freedom of Speech that the Same is Inseparable from Public Liberty", reproducida en Leonard W. Levy, Freedom of the Press from Zenger to Jefferson, Carolina Academic Press, Durham, North Carolina, 1996, especialmente p. 13. 
Igualmente, no sorprende que los argumentos areopagíticos a favor de la libertad de prensa traspasaran las fronteras oceánicas y fueran sucesivamente aprehendidos por la ideología colonial y revolucionaria norteamericana a lo largo del siglo XVIII, resonando en los primeros documentos que surcaron las colonias frente a la regulación restrictiva del libelo sedicioso vigente en el common law ${ }^{137}$, como reflejan los artículos periodísticos de Benjamín Franklin ${ }^{138}$ y la memorable defensa que del impresor Peter Zenger ofreciera Andrew Hamilton en 1735139, así como en los escritos de aquellos que adoctrinaron la Revolución, especialmente en los escritos a favor de la libertad de prensa del padre fundador de la independencia norteamericana, el mismo Thomas Jefferson ${ }^{140}$, notablemente influenciado por la repercusión que estaban teniendo los principios de la Areopagitica en la Francia revolucionaria, gracias a la adaptación que el Conde de Mirabeau ${ }^{141}$ había publicado en los meses previos a la convocatoria de los Estados Generales, reflejándose así la presencia e influencia de la Areopagitica en las dos Revoluciones atlánticas ${ }^{142}$.

Y tampoco sorprende que las doctrinas de la Areopagitica estén presentes en la concepción democrática de la libertad de expresión magistralmente articulada por John Stuart Mill en On Liberty (1859), la obra clásica a favor de la libertad individual, resonando el argumento miltoniano en defensa del encuentro abierto entre la verdad y el error en diversos párrafos de su segundo capitulo, dedicado a la libertad de pensamiento y discusion, of the liberty of thought and discussion ${ }^{143}$ :

137 Para un análisis más detallado, vid. mi estudio previo y bibliografia alli citada, María Nieves Saldaña, “A Legacy of Suppression” (II): Del control de la información y opinión en la América colonial y prerrevolucionaria. La Emergencia de la libertad de prensa", Derecho y Conocimiento. Anuario Jurídico sobre la Sociedad de la Información y del Conocimiento, vol. 3, 2004-2005, pp. 175-211.

138 Benjamin Franklin, An Apology for Printers, 10 de junio de 1731. El escrito es reproducido en Leonard W. Levy (ed.), Freedom of the Press, From Zenger to Jefferson, op. cit., pp. 3-10, especialmente p. 5 .

139 Vid. Livingston Rutherfurd, John Peter Zenger, His Press, His Trial and a Bibliography of Zenger Imprints. Also a Reprint of the Edition of the Trial, Dodd Mead, New York, 1904.

140 Vid. Thomas Jefferson, Proyecto de Ley sobre Libertad Religiosa, en Thomas Jefferson. Autobiografía $y$ otros escritos, estudio prelimiar y edición de Adrienne Koch y William Peden, traducción de Antonio Escochotado y Manuel Sáez de Heredia, Tecnos, Madrid, 1987, especialmente pp. 321-323.

141 Sobre la influencia ejercida por la Areopagitica en el pensamiento de Mirabeau, vid. Christophe Tournu, Milton et Mirabeau: Recontre Révolutionaire, Edimar, Paris, 2002; Tony Davies, "Borrowed Language: Milton, Jefferson, Mirabeau", en David Armitage, Armand Himy y Quentin Skinner (eds.), Milton and Republicanism, op. cit., pp. 264-271; Olivier Lutaud, "Des Révolutions d'Anglaterre à la Révolution Française. L'exemple de la Liberté de Presse ou Commnet Milton "ouvrit" les Etats Généraux", en La Légende de la Révolution. Actes du Colloque International de ClermontFerrand (juin 1986), Faculté des Lettres et Sciences Humaines de 1'Université Blaise-Pascal (Clemont II), Centre de Recherches Révolutionnaires et Romantiques, Diffusion Adosa, 1988, pp. 115 y ss.

142 Para un análisis más detallado vid. mi estudio previo y bibliografía allí citada, Maria Nieves Saldaña, "Recepción e influencia de la Areopagitica de John Milton en la ideología colonial y revolucionaria norteamericana: de Franklin a Jefferson", Historia Constitucional (Revista Electrónica), n. 13, 2012, pp. 661-696.

143 Sobre la influencia ejercida por la Areopagitica en la obra de Mill, vid, Alan Haworth, Free Speech, London and New York, Routledge, 1998, especialmente pp. 118-130, 224 y ss; Stewart Justman, The Hidden Text of Mill's Liberty, Savage, Rowman \& Littlefield, 1991, pp. 75-110. 
"But the peculiar evil of silencing the expression of an opinion is, that it is robbing the human race; posterity as well as the existing generation; those who dissent from the opinion, still more than those who hold it. If the opinion is right, they are deprived of the opportunity of exchanging error for truth: if wrong, they lose, what is almost as great a benefit, the clearer perception and livelier impression of truth, produced by its collision with error [...] Truth, in the great practical concerns of life, is so much a question of the reconciling and combining of opposites, that very few have minds sufficiently capacious and impartial to make the adjustment with an approach to correctness, and it has to be made by the rough process of a struggle between combatants fighting under hostile banners» ${ }^{144}$.

Sin embargo, la mayor similitud en los discursos a favor de la libertad de expresión de Milton y Mill no reside en la búsqueda de la verdad sino en el escepticismo que ambos manifiestan en su ulterior conquista, dada la constante persecución de las opiniones disidentes contrarias a los cánones morales y políticos ${ }^{145}$, defendiendo Mill, al igual que hiciera Milton, la virtualidad del libre embate de mentes y opiniones para potenciar el progreso individual y colectivo ${ }^{146}$, solo alcanzable cuando el libre desenvolvimiento de la individual ocupe un lugar prioritario en la sociedad, de ahí que la individualidad constituya, al mismo tiempo, presupuesto fundacional y limite del concepto de libertad que Mill propone, como queda patente en el tercer capítulo del ensayo, On individuality, as one of the elements of well-being ${ }^{147}$. Concepto que trata de conjugar su doble dimensión individual y colectiva, esto es, la necesaria conciliación del ejercicio racional de la libertad con el asfixiante panorama estandarizador que impone el principio de la mayoría en el sistema democrático ${ }^{148}$, asunto que constituye el núcleo del debate democrático, de ahí la visión plural y dinámica de la naturaleza humana que Mill postula, en continuo devenir, en constante proceso de transformación y perfección ${ }^{149}$. Punto de encuentro esencial con la energía

144 John S. Mill, On Liberty, Elizabeth Rapaport (ed.), Hackett Publishing Company, Inc., Indianapolis, Cambridge, 1978, pp. 16, 46. Para una traducción al español, vid. John S. Mill, Sobre la Libertad, prólogo de Isaiah Berlin, Alianza Editorial, Madrid, 1990.

145 "But, indeed, the dictum that truth always triumphs over persecution, is one of those pleasant falsehoods which men repeat after one another till they pass into commonplaces, but which all experience refutes. History teems with instances of truth put down by persecution [...] It is a piece of idle sentimentality that truth, merely as truth, has any inherent power denied to error, of prevailing against the dungeon and the stake», John S. Mill, On Liberty, op. cit., pp. 27, 28.

146 Ibid. pp. 32-33.

147 "If it were felt that the free development of individuality is one of the leading essentials of well-being; that it is not only a co-ordinate element with all that is designated by the terms civilisation, instruction, education, culture, but is itself a necessary part and condition of all those things; there would be no danger that liberty should be under-valued, and the adjustment of the boundaries between it and social control would present no extraordinary difficulty", ibid. p. 54 .

148 "If all mankind minus one, were of one opinion, and only one person were of the contrary opinion, mankind would be no more justified in silencing that one person, than he, if he had the power, would be justified in silencing mankind", ibid. p. 16.

149 Como señala Isaiah Berlin, "En el centro del pensamiento y de los sentimientos de Mill, está no su utilitarismo, ni su interés por el conocimiento, ni por separar el dominio público de lo privado... sino su apasionada creencia de que el hombre se hace humano mediante su capacidad de elección para el bien y para el mal [...] La imagen del hombre como creador, incapaz de 
politica que irradia el ensayo areopagitico, esa suerte de sinfonía inacabada que siempre representa el embate de mentes y opiniones, de ahí que el discurso milliano a favor de la libertad de expresión refleje el mismo dinamismo individual y colectivo, político y social, que irradian las doctrinas de la Areopagitica.

Por todo, el restrictivo discurso spinozista no tiene nada que hacer frente a la defensa de la libertad de expresión que ofrece John Milton en la Areopagitica, predeterminada por un concepto de libertad dinámico, predicable del individuo frente al poder, preconizando así el concepto moderno de libertad que consagró dos siglos más tarde John Stuart Mill en On Liberty. Por esto no sorprende que las doctrinas de la Areopagitica estén presentes en la formulación de la teoría del "free trade in ideas" que hizo célebre el conocido magistrado de la Corte Suprema de los Estados Unidos, el juez Oliver Wendell Holmes, en defensa de una interpretación más abierta de la Primera Enmienda de la Constitución norteamericana a principios del siglo $\mathrm{XX}^{150}$. Aunque, quizás la metáfora holmesiana del "mercado de las ideas" no habria alcanzado tal relevancia si no hubiese sido al mismo tiempo germinada, aprehendida y defendida por el notable constitucionalista norteamericano Zechariah Chafee, Jr., resonando el argumento areopagítico a favor del encuentro abierto de mentes y opiniones en uno de los escritos más influyentes de la historia constitucional de la Primera Enmienda, su Free Speech in the United States (1941) ${ }^{151}$. Por todo, finalmente, no sorprende que la Areopagitica esté considerada el ensayo fundacional de la libertad de expresión en la tradición constitucional euroatlántica ${ }^{152}$.

Fecha de envío / Submission Date: 20/04/2016

Fecha de aceptación / Acceptance Date: 23/05/2016

completarse a sí mismo; y por lo tanto nunca totalmente predecible: falible, compleja combinación de opuestos, algunos reconciliables, otros no susceptibles de ser resueltos o armonizados; incapaz de cesar en su búsqueda de la verdad, felicidad, novedad y libertad", vid. prólogo introductorio a John Stuart Mill, Sobre la Libertad, op. cit., pp. 32-33.

150 Vid. Abrams v. United States, 250 U.S. 616, 630 (1919) (Holmes, Jr., dissenting). Para un análisis más detallado vid. mi estudio previo y bibliografía allí citada, María Nieves Saldaña, "La génesis del Mercado de las Ideas: la Areopagitica de John Milton. Su recepción en la tradición jurídica norteamericana: Oliver W. Holmes y la Primera Enmienda", en E. Conde Naranjo (ed.), Vidas por el Derecho, Madrid, Universidad Carlos III de Madrid, 2012, pp. 59-100.

151 Zechariah Chafee, Free Speech in the United States, Harvard University Press, Cambridge, Massachussetts, 1942, especialmente pp. 31, 559.

152 Al respecto, vid. Murray Dry, The First Amendment Freedoms, Civil Peace and the Quest for Truth, op. cit., pp. 325-354, especialmente p. 329; Vicent Blasi, "John Milton's Areopagitica and the Modern First Amendment", Communications Lawyer, vol. 14, n. 4, 1996, pp. 12-19, especialmente p. 12; Mark A. Graber, Transforming Free Speech: The ambiguous Legacy of Civil Libertarianism, University of California Press, Berkeley, Los Angeles, Oxford, 1991, p. 3. 